Preliminary, not for quotation

\title{
SHORT-RUN EXCHANGE-RATE DYNAMICS: THEORY AND EVIDENCE
}

\author{
John A. Carlson, Purdue University \\ Christian M. Dahl, University of Aarhus \\ Carol L. Osler, Brandeis University
}

\begin{abstract}
Recent research has revealed a wealth of information about the microeconomics of currency markets and thus the determination of exchange rates at short horizons. This information should help in designing exchange-rate models. This paper analyzes an existing model that was previously demonstrated to be consistent with most of the major puzzles that have emerged under floating rates. It shows that this model is also consistent with most of the major new insights from microstructure. The model is consistent with the institutional structure of currency markets, it accurately reflects the constraints and objectives of major participants, and it fits key stylized facts concerning returns and order flow. [JEL classifications: F31, G12, G15]
\end{abstract}

August 2008

Corresponding author: Carol Osler, Brandeis University, Mailstop 032, Brandeis University, Waltham, MA 02454. Tel.: 781-736-4826. Fax: 781-736-2269. Email: cosler@brandeis.edu. The authors thank Gijoon Hong and Filippo Rotollo for excellent research assistance. Dahl gratefully acknowledges the research support of CREATES (funded by the Danish National Research Foundation). We take responsibility for all errors.

We take responsibility for all errors. 


\section{SHORT-RUN EXCHANGE-RATE DYNAMICS: THEORY AND EVIDENCE}

Research in currency market microstructure has taken off in the past decade, fueled by the new availability of data on foreign exchange trading. This research has revealed a wealth of evidence about the microeconomics of currency markets that can provide critical guidance for designing exchange-rate models. This paper presents an optimizing model of short-run exchange-rate dynamics consistent with this new micro evidence that is also consistent with a long list of older macro puzzles that continue to perplex researchers.

The main goal of currency market microstructure has always been to enhance our understanding of short-run exchange-rate dynamics. Because exchange rates are a critical link among economies, understanding exchange-rate dynamics is also critical for understanding most of the broader issues in international macroeconomics. For example, it is difficult to determine the relative merits of fixed and floating exchange-rate regimes, the consequences of rapid productivity growth in another country, or the world-wide consequences of a liquidity crisis if we do not know how these factors influence exchange rates.

Today's dominant exchange-rate model, the monetary model as embedded in the more comprehensive intertemporal optimizing framework of Obstfeld and Rogoff $(1995,2003)$, does not successfully capture short-run exchange-rate dynamics (Meese and Rogoff 1983; Flood and Taylor 1996; Lane 2001). This may reflect the many inconsistencies between the model's assumptions and the reality of currency markets. Charles Goodhart writes that, when serving as an adviser to the Bank of England, "I could not help but observe that some of the features of the foreign exchange ... market did not seem to tally closely with current theory..." (1988, p. 437). He also points out that "economists cannot just rely on assumption and hypotheses about how speculators and other market agents may operate in theory, but should examine how they work in practice, by first-hand study of such markets" (1988, p. 437). Frankel, Gali, and Giovannini made a complementary suggestion: "It is only natural to ask whether [the] empirical problems of the standard exchange-rate models ... might 
be solved if the structure of foreign exchange markets was to be specified in a more realistic fashion" (Frankel, Galli, and Giovannini 1996, p. 3). Burnside et al. (2007) argue that the structure of existing models, in which the failure of UIP is often dealt with by introducing an exogenous "risk premium" shock, is "fraught with danger" because it introduces "an important source of model misspecification that is likely to affect policy analyses." In essence, economists have been challenged to gather evidence about the microeconomics of currency markets and to use that evidence to design exchangerate models.

This challenge has deep roots. The critical role of evidence in scientific progress is a central message of Popper (1959). He reasons that when the evidence shows that a model is mis-specified in his parlance, the model has been "falsified" - scientists should design new ones. Many of the exchange-rate assumptions of today's dominant models seemed sensible when the models were developed but they have been falsified by subsequent research. For example, the mainstream international finance literature long ago showed that two key equilibrium conditions of the dominant models - purchasing power parity and uncovered interest parity - fail at short horizons, and microstructure research falsifies many others (Osler 2009).

Researchers have begun to take up the challenge of developing exchange-rate models consistent with today's best evidence, with contributions from Bacchetta and van Wincoop (2003), Evans and Lyons (2007), Chinn and Moore (2008), and Burnside et al. (2008). The main contribution of these models is to incorporate order flow as a key exchange-rate determinant. But the resulting models incorporate at most one or two of the myriad new insights from microstructure and thus remain inconsistent with much of the evidence. The first three of the models listed above assume, for example, that purchasing power parity holds continuously. This implies counterfactually that PPP is maintained by massive high-frequency flows related to goods-market arbitrage. Further, the models ignore these trades despite their stated incorporation of order flow. The model in Burnside et al. assumes counterfactually that dealers charge informed customers wider spreads than uninformed customers.

This paper outlines an optimizing model of short-run exchange-rate dynamics that is consistent with most of the new microstructure insights. The the essential features of the model are 
not new, however; they were developed independently by Black (1985), Driskill (1981), Osler (1995, 1998), and Hau and Rey (2002). These modelers shared the belief that to understand a given price, like the relative price of two currencies, one must understand the market in which that price is set. In consequence, this model captures key features of currency markets that have always been evident to market participants and keen observers and which are now revealed more broadly by the microstructure evidence.

Whether it helps models to accurately reflect market structures is an open question, of course. In support of the relevance of evidence, this paper uses calibrated simulations to show that our (relatively) accurate model predicts the various relations between order flow from different sources and returns now documented in the literature. In essence, the new microstructure research provides multiple out-of-sample tests for the model's underlying structure. The other macro-level models with or without microstructure features - do not predict these properties of order flow.

Since the goal of microstructure has always been to develop exchange-rate models of macro relevance, it is important to ask: Do the predictions of this microstructure-based model make progress in fitting the major exchange-rate puzzles associated with floating rates? The answer is: Yes. Unlike models that assume continuous PPP, this model predicts that PPP holds at long horizons but does not hold at short horizons, consistent with the evidence. This model predicts that exchange rates will appear poorly related to their fundamentals, at least to econometricians, consistent with the exchangerate disconnect puzzle. This model predicts that real exchange-rate volatility will rise upon the shift to floating rates (Flood and Rose 1995), consistent with the excess volatility puzzle. This model predicts that exchange-rate volatility will exceed the volatility of risk premiums and the volatility of interest differentials, consistent with the volatility puzzle; the model predicts that the autocorrelation of exchange-rate returns is close to zero even though that of interest differentials is fairly high, consistent with the persistence puzzle; the model predicts the failure of uncovered interest parity, consistent with the forward premium puzzle. One version of the model has been shown to out-predict the random walk (Driskill, Mark, and Sheffrin 1992).

Much of this empirical success has been documented already. We extend the macro evidence in support of the model by using it to explain the historical behavior of exchange-rate risk premiums, 
using quarterly data for five currency pairs. The key regression equation, which comes directly from the model, suggests that traditional risk premium regressions are mis-specified due to the exclusion of two important variables. The estimated coefficients are generally statistically indistinguishable from their predicted values and imply plausible speeds of convergence to long-run purchasing power parity (or its functional equivalent).

In our version of the model, most macro richness has been stripped out to enhance the focus on exchange-rate dynamics. In particular, we eschew variables, like the capital stock, that are unlikely to interact strongly with exchange rates at short horizons. With this transparent structure, the framework can be readily incorporated as the exchange-rate component of more complete models of the international economy.

Section I of the paper, which follows, describes the key agents in our optimizing model and shows how their behavior conforms to the new microstructure evidence. Section II describes equilibrium in the model and explains how our equilibrium condition also fits the new microstructure evidence. This section also shows how the model fits three familiar and important macro anomalies: the exchange-rate disconnect puzzle, the rise of real exchange-rate volatility under floating rates, and the failure of PPP at short horizons. Section III describes risk premiums in the model and in various extensions. Section IV uses calibrated simulations to show that the model fits key stylized facts from microstructure as well as two more macro anomalies: the volatility, and persistence puzzles. Section $\mathrm{V}$ shows that the model fits the historical behavior of quarterly currency risk premiums for five currency pairs. Section VI concludes.

\section{THE MODEL}

The microstructure research reveals that exchange-rate dynamics are crucially impacted by interactions among two major types of foreign exchange end-users: financial traders and commercial traders (Fan and Lyons, 2003; Bjonnes and Rime, 2006; Osler et al. 2008). For a model to fit the microstructure evidence, then, it must include both types of agents. Many microstructure-inspired models, such as Bacchetta and van Wincoop (2004a, 2004b), include only financial traders. This 
section describes our model's financial and commercial traders and explains how their assumed behavior fits the evidence.

\section{A. Financial Agents}

The model's financial agents, referred to as "speculators," take short-run currency positions in currencies, choosing rationally between domestic and foreign deposits. Their real-world counterparts would include managers at currency-focused hedge funds and commodity trading associations (CTAs), and proprietary traders at banks.

Profits are proportional to the speculator's bet, $b_{t}$, measured in units of foreign currency, and the excess return to foreign currency:

$$
\pi_{t+1}=b_{t}\left[s_{t+1}-s_{t}-d_{t}\right]
$$

Here, $s_{t}$ represents the $(\log )$ spot exchange rate at time $t$, measured as domestic currency units per foreign currency unit; and $d_{t}$ is the interest rate differential, $d_{t}=r_{t}-r_{t}^{*}$, where $r_{t}^{*}$ and $r_{t}$ represent foreign and domestic interest rates, respectively.

Following common practice in the finance literature, financial traders have CARA utility. This will ultimately be equivalent to quadratic utility since returns will be normally distributed under the standard assumption that shocks are normally distributed:

$$
W_{t}=E_{t}\left(\pi_{t+1}\right)-(\theta / 2) \operatorname{Var}_{t}\left(\pi_{t+1}\right)
$$

Here, $W_{t}$ represents expected welfare conditional on information at time $t, \theta$ is risk aversion, $E_{t}\left(\pi_{t+1}\right)$ denotes the expected value of profits during period $t+1$ conditional on information at time $t$, and $\operatorname{Var}_{t}\left(\pi_{t+1}\right)$ denotes the conditional variance of profits based on information as of time $t$. As is well known, the speculator's optimal position under CARA is proportional to expected profits and inversely proportional to risk aversion and risk itself:

$$
b_{t}=\left[E_{t}\left(s_{t+1}\right)-s_{t}-d_{t}\right] / \theta \operatorname{Var}\left(s_{t+1}\right) .
$$

$\operatorname{Var}\left(s_{t+1}\right)$ is the expected variance of the exchange rate conditional on information at time $t$. If the distribution of exogenous shocks is constant, $\operatorname{Var}\left(s_{t+1}\right)$ is constant as well. This is assumed here. The expected excess return to foreign currency is, of course, the risk premium: $r p_{t} \equiv E_{t}\left(s_{t+1}\right)-s_{t}-d_{t}$. When the risk premium is positive speculators borrow domestic currency and buy foreign currency; when 
the risk premium is negative speculators do the opposite. Note that this implies a downward-sloping demand curve for foreign currency. Given the expected future value of the foreign currency, a lower current value provides higher expected return, other things equal, raising demand.

Net purchases by financial traders are the change in the financial traders' aggregate desired foreign-currency position. For the present we assume that the number financial traders is set exogenously at $N$, though this is later endogenized. Aggregate net speculative demand is: $N\left(b_{t}-b_{t-1}\right) \equiv$ $N q\left(r p_{t}-r p_{t-1}\right)$, where for convenience $q \equiv 1 /\left[\theta \operatorname{Var}\left(s_{t+1}\right)\right]$.

\section{B. The Model's Financial Traders and the Evidence}

The financial traders outlined above have three key properties: (i) they are motivated by profits, (ii) they are constrained in their risk-taking, and (iii) they trade in highly liquid assets in flexible supply, such as deposits. These properties conform to the institutional reality of currency markets but are not universally assumed in exchange-rate models. We consider each property in turn.

Profits, not consumption: In practice a large share of most financial traders' compensation, often more than half, comes from an annual bonus determined primarily by his profits. ${ }^{1}$ However, the familiar intertemporal optimizing model (Obstfeld and Rogoff 2003) assumes that financial traders are motivated by consumption rather than profits, and consumption certainly seems like the deeper fundamental variable. But in reality consumption seems unlikely to have any influence on speculative currency trades due to agency problems inherent in most trading operations.

Currencies are traded in a wholesale market where the average trade size exceeds $\$ 1$ million. Thus the vast majority of currency trades are initiated by institutions such as banks, corporations, and asset managers - indeed, retail currency trading, though growing rapidly, is still almost invisible statistically. ${ }^{2}$ Since almost all traders are employees, their objectives - and thus the factors that influence trading and exchange rates - are largely determined by the incentive structures established

\footnotetext{
${ }^{1}$ Agency problems in currency markets are not yet the subject of widespread research, but they seem likely to be an important influence on reality. Bensaid and DeBandt (2000) have already explained the use of stop-loss limits for currency traders using agency theory. Agency problems more generally have been a major theme in corporate finance research since Jensen and Meckling (1976), and the real-world importance of such issues was recently highlighted anew by a wave of major corporate scandals.

${ }^{2}$ Though exact statistics do not seem to exist, sources at the Bank for International Settlements and in the private sector estimate informally that retail trades account for less than one percent of total currency trading. Even that bit only registers its existence when banks aggregate individuals' currency needs bring them to the wholesale market.
} 
by their firms. These incentive structures, in turn, are determined by shareholder objectives subject to the constraints of asymmetric information and reporting structure. Consumption - and consumption risk - will influence financial trading only if shareholders are motivated by consumption and they motivate their currency traders by consumption.

It does not appear that shareholders are motivated by consumption in this market. Hedge funds and CTAs, for example, where owners are also managers, are normally paid a fraction of assets under management (normally 1 percent) and a fraction of profits (normally 20 percent, according to Lowenstein (2000)). Bank shareholders would include asset management institutions, such as endowments and pension funds, as well as individuals. Asset management institutions are explicitly motivated to maximize shareholder value subject to a risk budget because they are rated on these criteria by agencies such as Morningstar. Individual shareholders might consider consumption in their portfolio choices, but they would do so despite instruction to the contrary since finance education uniformly stresses Markowitz portfolio selection theory (focused exclusively on risk and return).

Even if shareholders were concerned with consumption rather than profits, traders might not be so motivated due to the many layers of agency relationships within such firms. At a large bank, for example, the line of responsibility runs through the Board of Directors, the CEO, the Treasurer, and the global head of trading before reaching the proprietary traders. Asymmetric information plagues every link in this chain, so consumption-based incentive schemes might not necessarily align the interests of traders with those of shareholders. The practice at banks today is to motivate speculative currency traders by paying them huge bonuses determined by the trader's own profits and by the profits of the trading floor as a whole. Since consumption does not enter this picture it would take a creative imagination to construct a realistic scenario in which consumption risk has substantial influence on the behavior of financial traders.

Constrained risk-taking: Currency traders at financial institutions are invariably subject to explicit loss- and position-limits.

[B]anks have long maintained clearly established volume or position limits on the maximum open position that each trader or group can carry overnight, with separate - probably less restrictiveintraday or "daylight" limits on the maximum open position that can be taken during the course of a 
trading session. These limits are carefully and closely monitored, and authority to exceed them, even temporarily, requires approval of a senior officer (Cross, 1998).

Such limits are considered essential to control agency problems, especially the risk that a "rogue trader" might accumulate huge losses unbeknownst to management. A single rogue trader - like Nick Leeson of Barings (prison beginning 1995) or John Rusnack of Allied Irish Banks (prison beginning 2001) - can bring down an entire firm. Speculators' risk-taking is also constrained because they face the gambler's ruin problem: a long series of losses will put them out of a job (Carlson 1998). The traders themselves may or may not be risk averse, but by modeling them as risk averse we capture their unwillingness to take infinitely large positions.

Highly liquid assets in flexible supply: For active currency speculators, standard practice is to trade in highly liquid assets in flexible supply, such as deposits or even forward or futures contracts or. These are preferred to bonds (including government securities) and equities because of their lower transactions costs. Financial-customer bid-ask spreads for spot and forward trades typically range from two to ten basis points (Osler et al. 2008) and transaction costs in currency futures markets are roughly comparable (Giddy 1983). By contrast, spreads in equity markets average roughly 50 basis points (Madhavan et al. 1997) and those on Treasury bonds range upward from 80 basis points (Fleming 1997). The financial currency traders in our model use liquid assets in flexible supply but those in other microstructure-inspired models typically trade bonds that are in fixed supply (e.g., Bacchetta and van Wincoop (2004a, 2004b)).

Forward trades technically involve two transactions, one in the spot market and a second in the swap market, which means that forward transactions contribute directly to the spot market order flow on which our analysis focuses.

\section{Commercial Agents}

We next outline a sub-model of rational currency demand from non-financial firms. ${ }^{3}$ We note in passing that commercial trade in currencies is often assumed, incorrectly, to be an extremely small fraction of currency trading. In fact, commercial trades account for about one third of end-user

\footnotetext{
${ }^{3}$ The model's commercial agents represent a class of agents familiar from standard finance models who "want to maximize price when selling and minimize price when buying" rather than "to maximize their trading profits" (Harris 1998, p. 5).
} 
transactions (B.I.S. 2007). Today's microstructure evidence confirms their importance by showing that commercial and financial firms behave very differently and that their interactions are an essential part of the exchange-rate determination process. Exchange-rate models clearly risk empirical irrelevance if these agents are incorrectly modeled. Nonetheless, their treatment in other models is typically casual, at best. In Chinn and Moore (2008), commercial and financial agents are indistinguishable. In Bacchetta and van Wincoop (2005?) it is assumed counterfactually that commercial firm behavior is purely random. In Entem () it is assumed, equally counterfactually, that these agents are actually a type of investor.

There are $K$ domestic firms producing output $Y$ using an imported input $B^{*}$ according to the following production function: $Y=B^{*^{1 / 2}}$. The firm's profits are $\Pi=P Y-\hat{s} P^{*} B^{*}$, where $P\left(P^{*}\right)$ is the domestic (foreign) price level and $S$ is the actual (not log) exchange rate. Imports of a profit-maximizing firm, $\tilde{B}^{*}$, are: $\tilde{B}^{*}=\left(P / 2 S P^{*}\right)^{2}$. Each domestic firm's foreign exchange purchases per period, $P^{*} \widetilde{B} *$, necessarily respond negatively to an appreciation of the home currency. The imported input could be a raw material, a capital good, or even consumption goods intended for ultimate retail sale.

Meanwhile, $K^{*}$ foreign firms produce output $Y^{*}$ using an input $B$ purchased from the home country. The foreign production function parallels the domestic one: $Y^{*}=B^{1 / 2}$. The firm's profits are $\Pi^{*}=P^{*} Y^{*}-P B / S$. Optimal imports of a profit-maximizing foreign firm, $\tilde{B}$, are: $\tilde{B}=\left(P^{*} S / 2 P\right)^{2}$. Each foreign firm's foreign exchange sales per period, $P \tilde{B} / S$, respond positively to an appreciation of the home currency (decline in $S$ ).

Net foreign currency demand from these firms is $P^{*} \tilde{B} *-P \tilde{B} / S=K\left(\frac{1}{2 R}\right)^{2}-K *\left(\frac{R}{2}\right)^{2}$, where we define the real exchange rate as $R=P^{*} S / P$. This shows that influence of the nominal exchange rate on commercial demand works exclusively through the real exchange rate. Net commercial demand responds negatively to an appreciation in the foreign currency.

Assume for convenience that there are no speculators and a symmetric long-run equilibrium exists in which $K=K^{*}$ and $R \equiv P^{*} S / P=1$. At this equilibrium the sensitivity of commercial demand 
to proportionate exchange-rate changes simplifies greatly: $\frac{\partial}{\partial S / S}[K P * \widetilde{B} *-K * P \widetilde{B} / S]=-K$.

Furthermore, at this equilibrium the nominal log exchange rate is determined by a condition similar to purchasing power parity: $\bar{s}=\ln \left(P / P^{*}\right)$. We use these expressions as the basis for a linearized version of commercial demand:

$$
F X_{t}=\ln \left(P_{t} / P_{t}^{*}\right) K-K s_{t} \equiv C_{t}-K s_{t}
$$

This maintains both the long-run equilibrium rate shown above and the theoretical sensitivity of commercial demand to proportionate exchange-rate changes.

\section{The Model's Commercial Traders and the Evidence}

The commercial traders outlined above have three key features: they do not speculate and they respond swiftly to exchange-rate levels.

Absence of Speculation: Shouldn't commercial traders also speculate, to make the model internally consistent? In the model of Onur (2008), for example, the order flow of "commercial traders" in is driven entirely by speculative motives. Unfortunately, achieving internal consistency this way imposes external inconsistency. According to Goodhart (1988), less than five percent of large corporate customers speculate in spot or forward markets. Dealers consistently confirm this, as do corporate treasurers with whom we spoke personally. Indeed, it turns out that traders at many commercial firms are explicitly prohibited from making trades that are not explicitly motivated by their real-side productive activities.

Within our simple model the corporate decision not to speculate may not seem sensible: if it's rational for financial firms to speculate it should also be rational for commercial firms to speculate. In the more complex setting of reality, however, the rationality of the decision not to speculate becomes quickly apparent: it is both risky and expensive to manage currency speculation and the high costs are likely to outweigh any potential benefits at commercial firms. These high costs arise in part from the large staff required to control rogue trader risk. Responsible firms must handle clearing and settlement separately from trading, which requires a separate set of employees under separate managers. In the 
Federal Reserve Bank of New York’s guidelines for “Managing Operational Risk in Foreign

Exchange," Number 40 reads as follows:

Segregation of Duties: Operations personnel should maintain a reporting line independent of sales and trading. ... Having one individual responsible for both the settlement process and the trading process; issuing and authorizing payment instructions; ... makes it much more likely that any fraudulent activity will go undetected for some time (page 31 ). ${ }^{4}$

Similarly, the Foreign Exchange Committee, an industry self-monitoring group, asserts that "an important aspect of risk management is ... the segregation of trading room and back-office functions."

In addition to hiring a separate back-office staff, the commercial firm determined to speculate in currencies would have to hire a third set of employees, known as "compliance officers," to ensure that the traders and the back-office staff play by the rules. According to The Federal Reserve Bank of New York's Best Practice 48 (p. 34), an audit staff that is independent of both trading and operations "plays a very important role. It ensures that the controls in place are in fact working properly... [and] should help management uncover any problems before they lead to financial loss."

Commercial firms avoid speculation, while financial firms do not, in part because rogue trading risk at commercial firms is intensified by their lack of expertise in foreign exchange trading. For this and other reasons the corporate world has concluded that it is best for firms to focus on their "core competencies." This informal but influential conclusion is now supported by empirical research documenting the lackluster performance of diversified firms relative to more focused firms (Lang and Stulz 1994, Berger and Ofek 1995). Commercial firms' core competencies do not include currency speculation and financial firms' core competencies do not include real-side production.

Our model cannot tractably represent intra-firm agency problems or the importance of core competencies. It can nonetheless, capture the behavior induced by these real-world complexities by assuming that commercial traders do not speculate. Fortunately, this modeling choice is without loss of generality. The essential feature of the model here is heterogeneity: if all agents are rational, currency trading must be driven by both speculative and non-speculative motives in order to generate realistic amounts of trading volume (Milgrom and Stokey 1982, Morris 1982). The model can be

\footnotetext{
${ }^{4}$ The segregation of front- and back-office responsibilities is also forcefully recommended in the Federal Reserve Bank of New York's guidelines for “Nondealer Participants” (Federal Reserve Bank of New York 2004).
} 
internally consistent if we reinterpret the trading of commercial agents as the non-speculative component of all agents' behavior and the trading of financial agents as the speculative component of all agents' behavior.

In theory, corporate hedging decisions could represent an indirect route through which speculative motives might influence commercial currency demand. When they expect the currency to move in their favor, for example, corporations might choose to rely less on the forward market and more on the spot market. To investigate this possibility we learned about current corporate best practice from textbooks such as Dearson (2002) and Hakala and Wystup (2009). ${ }^{5}$ As described consistently in these texts, a corporation's decision regarding the appropriate fraction of future exposure to hedge is driven by the tradeoff between anticipated volatility and the transaction costs of hedging. Anticipated currency returns are not a major factor, presumably because corporate treasurers and their staff do not consider themselves qualified to do exchange-rate forecasting. ${ }^{6}$ It is also important to note that hedging decisions are taken at relatively low frequencies, such as one quarter or one year, not at the high frequencies relevant to short-run exchange-rate dynamics. In short, hedging does not introduce a significant speculative component to commercial currency demand.

Demand Responds Swiftly to Exchange-Rate Levels The effect of exchange rates on commercial demand has been amply documented at macro time horizons. This effect also applies at higher frequencies, as shown by microstructure research. Traders at commercial firms often instruct the foreign exchange dealers at their banks to buy a certain amount of currency if its value falls to a pre-specified level, or vice versa. These instructions, called "take-profit orders, are rational when agents have liquidity needs that are not immediate (Osler 2003, 2005). ${ }^{7}$ To illustrate, Figure 1 shows all outstanding take-profit orders at the Royal Bank of Scotland, the world's fifth largest dealing bank, at the (entirely arbitrary) moment of 20:53 G.M.T. on January 26, 2000. The negative relationship

\footnotetext{
${ }^{5} \mathrm{We}$ also had conversations with corporate treasury officials from various U.S. firms to confirm informally that the textbook recommendations are actually followed.

${ }^{6}$ Since exchange-rates so closely approximate a random walk, this is probably wise.

${ }^{7}$ The motivation for using take-profit orders is best understood in terms of options. Suppose a customer needs currency but not instantly. The customer effectively owns the option to trade at a better price later. Since options are valuable so long as volatility is positive, trading immediately would be equivalent to throwing away the value of the option. Additional costs and benefits of placing orders rather than dealing immediately are discussed in Handa and Schwartz 1996, Foucault 1999, and Hollifield et al. 2002, inter alia.
} 
between the exchange-rate level and this component of currency demand is readily apparent. Every dealing bank has its own book of take-profit orders, so this represents one portion of the market's overall instantaneous demand curve at that time. Negative-feedback trading is also carried out by the "Japanese exporters" who loom large in daily conversations within the foreign exchange market. These firms convert huge quantities of dollars to yen and choose a rate every day at which they want to sell those dollars. The firms instruct their (in-house) traders to sell if the target rate is reached. In aggregate, the take-profit orders on the books of individual banks, together with implicit pricecontingent demand from agents like the Japanese exporters, effectively create an instantaneous demand curve for currency of the sort captured by our model.

\section{EQUILIBRIUM}

We complete our description of the model by discussing how financial and commercial agents interact to determine exchange rates.

\section{A. Equilibrium: A Broad Characterization}

In equilibrium, net end-user purchases of currency must equal net end-user sales:

$$
0=N\left(b_{t}-b_{t-1}\right)+\left[C_{t}-K s_{t}\right]=N q\left(\left[E_{t}\left(s_{t+1}\right)-s_{t}-d_{t}\right]-\left[E_{t-1}\left(s_{t}\right)-s_{t-1}-d_{t-1}\right]\right)+\left[C_{t}-K s_{t}\right] .
$$

Under the assumption of rational expectations this equilibrium condition becomes:

$$
E_{t} s_{t+1}-(1+K / N q) s_{t}-E_{t-1} s_{t}+s_{t-1}=-C_{t} / N q+\Delta_{t},
$$

where $\Delta_{t} \equiv d_{t}-d_{t-1}$ represents the change in the interest differential.

The bubble-free solution, derived in the Appendix, is this:

$$
s_{t}=\lambda s_{t-1}+(1-\lambda) \sum_{j=0}^{\infty} \lambda^{j}\left(E_{t} C_{t+j}-\lambda E_{t-1} C_{t+j}\right) / K-\frac{\lambda}{1-\lambda} \sum_{j=0}^{\infty} \lambda^{j}\left(E_{t} \Delta_{t+j}-\lambda E_{t-1} \Delta_{t+j}\right) .
$$

The term $\lambda$ is the smaller root of the associated characteristic equation; $\lambda$ rises monotonically with speculative activity from a lower bound of zero to an upper bound of unity (see Appendix A). In equilibrium, speculative activity is positively influenced by the number of speculators and negatively influenced by their risk aversion and by exchange-rate risk.

Equation (7) shows that the current exchange rate depends on its own lagged value, on expected future values of $C_{t}$ (representing exogenous influences on commercial demand), and on 
expected future values of $\Delta_{t}$, the change in the interest differential (representing exogenous influences on financial demand). The dependence of today's asset price on expected future fundamentals is a property shared with all modern models of financial prices.

\section{B. Equilibrium and the Microstructure Evidence}

There are five key features of this equilibrium condition that merit discussion. First, we assume neither PPP nor UIP but instead derive these or related conditions as endogenous outcomes. Second, the model includes no dealers but it does capture commercial and financial order flow. Second, there is an inverse relationship between commercial and financial order flow. Third, commercial order flow should be positively related to a country's current account. Fourth, the model includes no constraints on the aggregate supply of deposits. Fifth, money supplies are not explicitly modeled.

PPP: Most models of short-run exchange-rate dynamics, including others incorporating insights from microstructure, continue to assume that exchange rates are set according to continuous PPP or its functional equivalent (e.g., Obstfeld and Rogoff 1995 2003; Bacchetta and van Wincoop 2004a, 2004b; Chinn and Moore 2008). The evidence on this parity relation is well-known and overwhelming: PPP does not characterize the data at horizons below a few years; it is not even a decent approximation.

In models focused on the connections between exchange-rate dynamics and order flow this is especially problematic for two reasons. First, it is counterfactual and thus it seems to collide with the original motivation for microstructure research. Second, it assumes away the goods-market arbitrage that makes PPP hold, so an important portion of order flow is excluded from the model. In our model, the order flow associated with goods-market arbitrage is explicitly modeled, PPP (or the equivalent) emerges endogenously as a property of long-run equilibrium, and we can analyze the dynamics with which PPP is restored after deviations.

Our model also does not assume UIP but instead derives a related condition as an endogenous outcome (this is discussed at length below). In many of today's models the failure of UIP is ensured solely by an exogenous "risk premium" shock. As noted by Burnside et al. (2007), this is "fraught 
with danger" because it introduces "an important source of model misspecification that is likely to affect policy analyses." Burnside et al. (2007) attempt to model the failure of UIP using a model that incorporates insights from equity-market microstructure. Specifically, Burnside et al. assume that dealers cope with adverse-selection risk by charging wider spreads to their most informed customers, as is true in equity markets. In currency markets, however, adverse-selection is unimportant in the dealer-customer relationship: dealers benefit from trading with the best informed customers. In consequence, the best-informed currency customers pay the narrowest spreads (Osler et al. 2008).

No Dealers: The macro sketched above is tractable in part because it has no dealers. Nonetheless, it is fully consistent with the structure of currency trading at macro horizons. To understand this it is helpful to recall that dealers essentially facilitate intraday trading among endusers. ${ }^{8}$ Since the dealing community as a whole carries negligible inventory overnight, end-users must be the relevant liquidity providers to each other at horizons of a day or more (Bjønnes and Rime 2006). The horizon of our model is at least one day, so it is reasonable to abstract from dealers entirely. To the limited extent that dealers take positions across trading days they would already be included in the model as financial traders.

The commercial and financial net purchases that are explicitly modeled here are thus conceptually consistent with commercial and financial order flow as it is measured in empirical work. Order flow is defined as buyer-initiated trades minus seller-initiated trades. For end-users this is just their buy trades minus their sell trades, since end-users initiate all their trades by calling their dealers. This is another way in which the model is consistent with the microeconomic structure of the currency market. Of course, the model cannot incorporate every institutional feature and remain tractable, so dealers are not explicitly modeled, but this does not make any of the model's assumptions less consistent with reality. In our model, as in reality, commercial and financial customers choose an amount to trade conditional on observed exchange rates, and exchange rates adjust by the end of each day to ensure that the net purchases of one group over that day equal the net sales of the other group. Dealers are also excluded from the microstructure-inspired models of Bacchetta and van Wincoop

\footnotetext{
${ }^{8}$ This is embodied in the Evans and Lyons (2002) model as follows: each day has three trading rounds. In Round 1 end-users call their dealers and trade, forcing the dealers to take on inventory. In Round 2 dealers trade with each other. In Round 3 dealers eliminate their inventory positions by trading with additional end-users.
} 
(2004a, 2004b) and Chinn and Moore (2008), as well as from macro-level models of other important markets like the automobile market (e.g., Hall and Rust date).

Inverse Relationship Between Commercial and Financial Order Flow: A key empirical regularity from currency microstructure research is that cumulative financial order flow is positively related to concurrent exchange rate levels while cumulative commercial order flow is negatively related. The conclusion arises in Lyons' (2001) study of monthly customer flows at Citibank; in Evans and Lyons' (2005) study of daily and weekly customer flows at the same bank; in Marsh and O'Rourke's (2005) analysis of daily data from another large dealing bank; and in Bjønnes and Rime's (2005) study of overnight trading in Swedish kroner. Standard macro models, however, cannot characterize the relationship between commercial and financial currency flows because they assume continuous PPP (or the equivalent with respect to the terms of trade) and continuous uncovered interest parity (UIP) without modeling the currency trading that maintains these conditions.

The microstructure evidence also provides an explanation for the signs of the relationship between end-user order flow and exchange-rate returns. Commercial agents apparently provide overnight liquidity to financial agents, according to the following mechanism: financial-trader net purchases begin the process and push the exchange rate; by the end of the day the rate must move enough to draw in the required overnight liquidity from commercial agents. ${ }^{9}$ Bjønnes et al. (2005) uses comprehensive data on trading in Swedish kroner to show that overnight commercial demand tends to lag financial demand, consistent with this liquidity provision hypothesis. Marsh and O'Rourcke (2005) shows that commercial demand lags returns while financial demand does not.

Our model implies that commercial and financial net purchases will be inversely related to each other, which is one part of this empirical regularity under discussion. However, in any given period commercial demand could be either positively or negatively related to exchange-rate returns, because in our model both sets of firms provide a "downward sloping demand curve," as noted above.

\footnotetext{
${ }^{9}$ But - the reader may be wondering - isn't liquidity supplied by currency dealers? It is important here to distinguish between immediate liquidity suppliers and ultimate liquidity suppliers. FX dealers supply immediate liquidity. But dealers generally choose to hold zero inventory overnight so when one customer holds a position overnight the dealer must find an ultimate liquidity supplier to take over the position. Indeed, the extent to which dealers adjust prices in response to demand presumably reflects the price responsiveness of ultimate liquidity suppliers. According to the evidence accumulated to date, the ultimate liquidity suppliers seem to be commercial agents.
} 
This means that each agent's demand can respond endogenously to exchange-rate changes, in which case the agent provides liquidity to other agents, or it can respond to exogenous shocks, in which case the agent absorbs liquidity. As shown in Section IV, below, the (endogenous) overall correlation between commercial demand and returns is generally negative, consistent with the evidence.

Commercial order flow and the current account. Our interpretation of commercial agents as representing primarily importers and exporters implies that net demand from these agents should be strongly related to the current account. This implication is supported by microstructure evidence. Bjønnes et al. (2005) shows that net commercial demand for Swedish kroner is positively related to the Swedish current account and trade balance.

No Asset Supply Constraints. Though it is traditional to assume that asset supplies are constrained and that these constraints influence exchange rates, the evidence does not support this. Indeed, researchers sought in vain for such evidence throughout the 1980s. The absence of such evidence seems natural once we recognize that short-term currency speculators generally choose to speculate via time deposits or forward contracts, as discussed earlier. Since monetary policy today focuses on interest-rate control, demand for these deposits and forward contracts could rise substantially without bringing any significant change in interest rates. In effect, the supply of the assets is highly elastic, consistent with our model.

Money Supply? The equilibrium condition used here differs notably from the joint equilibrium condition that has been standard in international economics for decades: stock equilibrium in domestic and foreign money markets combined with continuous purchasing power parity (Mussa 1976, Branson 1975, Obstfeld and Rogoff 1995). Together, these two conditions imply elegantly that "the exchange rate [is] the relative price of two monies" (Kreuger 1983, p. 62). This joint equilibrium condition became popular after a critical conceptual flaw was identified in the earlier "flow" models of exchange-rate determination, specifically the assumption that expected returns determine changes in asset holdings (e.g., Mundell 1963, Fleming 1962) rather than the level of asset holdings. Notably, this assumption was unrelated to the older models' equilibrium condition that flow demand for currency equals flow supply. Indeed, there was at the time little evidence concerning this 
equilibrium condition, either for it or against it. Nonetheless, all major models since then have used the condition of money-stock equilibrium combined with PPP.

At the time of this shift it was widely thought to be innocuous, since stock equilibrium can be equivalent to flow equilibrium under certain conditions. However, exchange-rate models based on money-stock equilibrium have had limited success at capturing short-run exchange-rate dynamics (Meese and Rogoff 1983, Engle and Flood 2005). ${ }^{10}$ This indirect evidence against the standard equilibrium condition is now augmented by more direct evidence suggesting, among other things, that money is not a critical fundamental for exchange rates: rates react very little, if at all, to money supply announcements, though they react strongly to announcements of GDP, inflation, and other likely fundamentals (Cai et al. 2001, Anderson et al. 2003).

The possible irrelevance of money supplies for short-run exchange rates is supported by a further insight from currency microstructure: exchange rates are primarily determined by order flow within the currency market (see Lyons 1995, Goodhart and Payne 1996, Evans 1998, Evans and Lyons 2002), where order flow is buy-initiated trades minus sell-initiated trades. A currency appreciates when interdealer order flow is dominated by buy-initiated trades and depreciates when it is dominated by sell-initiated trades. Interdealer order flow can explain up to 60 percent of daily exchange-rate returns (Evans and Lyons 2002) while standard international macro models typically explain under ten percent. The possibility that these results reflect causation from returns to order flow has been carefully examined and rejected (Evans and Lyons 2003, Danielsson and Love 2005). ${ }^{11}$ From a finance perspective, the influence of order flow is not surprising. Evidence has long existed that order flow is an important determinant of U.S. equity returns (e.g., Shleifer 1986, Holthausen et al. 1990) and more recent evidence shows that order flow also an important determinant of bond returns (Fleming 2003, Brandt and Kavajecz 2005, Pasquariello and Vega 2005).

\footnotetext{
${ }^{10}$ We stress the limited scope of this analysis. At long horizons the standard money market equilibrium condition is theoretically and empirically supported. At any horizon stock equilibrium seems to be an appropriate equilibrium condition in equity and bond markets.

${ }^{11}$ Beyond the statistical evidence there is also a common-sense reason for taking seriously the importance of order flow. Dealers design their trading strategies around the idea that buying and selling pressure determines exchange rates. Dealers have made money successfully under floating rates for over three decades: Under the popular hypothesis of individual rationality dealers would know by now if order flow were unimportant.
} 
The importance of currency-market order flow for exchange-rate determination suggests that stock equilibrium is never equivalent to flow equilibrium because some changes in stock positions are not accompanied by flows through currency markets. If all traders are investors, as is often assumed, then any increase (decrease) in stock demand for a given currency brings corresponding purchases (sales) in currency markets. However, commercial traders are a significant force in currency markets, and changes in a commercial firm's currency holdings often take place outside of currency markets. Suppose a commercial firm buys currency and uses it to pay for imported goods. The firm generates a flow in currency markets when it buys the currency but no flow in the market when it sends the currency to the firm that supplies its imports. Further, since the supplying firm does not view the currency as "foreign," receipt of the funds also does not prompt further trades in currency markets. (Instead, the foreign firm will initially hold the funds as cash and ultimately use them to pay its normal - largely domestic - expenses.)

The well-documented importance of order flow for exchange-rate determination directs us back to the old equilibrium condition that focused on currency flows, that is, the requirement that enduser net purchases equals end-user net sales within a given period. Indeed, this condition inescapably constrains the market every trading day (unless dealers depart from standard practice and hold large overnight positions), and certainly constrains the market week by week. ${ }^{12}$ In our model, this is the constraint that determines exchange rates.

Note, however, that financial traders in our model are entirely rational. Thus our model of short-run exchange rates adopts the best of the earlier approaches: exchange rates are determined by currency flows, as the evidence shows, while international asset holdings are chosen rationally.

\section{Equilibrium: A Closed-Form Solution}

To derive a closed-form solution for exchange rates, the exogenous forces $-C_{t}$ for commercial traders and $\Delta_{t}$ for financial traders - must be specified more narrowly. It is convenient to suppose at present that $C_{t}$ is subject to i.i.d.-normal, mean-zero shocks denoted $\varepsilon_{t}: C_{t}=\bar{C}+\varepsilon_{t}$. In this case, $E_{t} C_{t+j}=\bar{C}$ for all $j>0$. These shocks can be interpreted as inevitable high-frequency

\footnotetext{
${ }^{12}$ It is ironic that this evidently binding constraint is not used in exchange-rate models while constraints that are known to be non-binding, such as continuous PPP, are ubiquitous.
} 
unevenness in the stream of commercial currency demand. Alternatively, the shocks permit us to broaden the components of currency demand captured by the model. The shocks could represent payment of investment income, unilateral transfers, or foreign direct investment. They could also capture non-speculative capital flows such as official foreign-exchange intervention and aid. Given the underlying dependence of $C_{t}$ on price levels it is not empirically satisfactory to assume that shocks are i.i.d.; later we permit $C_{t}$ to be disturbed by permanent as well as transitory shocks.

We assume interest differentials are mean-reverting, consistent with evidence provided by McCallum (1994) and others. As in Mark and Wu (1998), we also assume that interest differentials are exogenous. Since country's monetary policy is the main determinant of a country's short-run interest rates, and since monetary policy is exogenous from a short-run perspective, this seems to be a reasonable representation of reality. Nonetheless, the exogeneity of interest rates is not critical. ${ }^{13} \mathrm{We}$ also assume that interest differentials are stationary, and more specifically that they are $\operatorname{AR}(1): d_{t}=$ $\rho d_{t-1}+\eta_{t}$, where $0<\rho<1$ and $\eta_{t}$ represents a normally distributed, mean zero, i.i.d. shock. (We assume zero correlation between $\varepsilon_{t}$ and $\eta_{t}$.)

With these assumptions, the solution for the exchange rate becomes (details in Appendix):

$$
s_{t+1}=\bar{s}+\lambda\left(s_{t}-\bar{s}\right)+(1-\lambda) \varepsilon_{t+1}-\frac{\lambda}{1-\rho \lambda} \eta_{t+1}+\frac{\lambda(1-\rho)}{1-\rho \lambda} d_{t}
$$

The first term on the right-hand side of (8) is the long-run exchange rate in the absence of speculators.

In any period the no-speculator equilibrium would be $C_{t} / K$, with long-run average value $\bar{s} \equiv \bar{C} / K$. The second term shows that the exchange rate eliminates the fraction $1-\lambda$ of any gap between $s_{t}$ and $\bar{s}$ in each period. Since the remaining three exchange-rate determinants $\left(d_{t}, \varepsilon_{t+1}\right.$, and $\left.\eta_{t+1}\right)$ all have a central tendency of zero, the long-run exchange rate is $\bar{s}=\bar{C} / K$ in the presence of speculators, the same as its long-run equilibrium without speculators.

The third term on the right-hand side of (8) shows that a positive shock to commercial foreign-currency demand, $\varepsilon_{t}>0$, tends to appreciate the foreign currency, other things equal. The

\footnotetext{
${ }^{13}$ Interest rates are endogenous in closely related models, including Black (1985), Driskill and McCafferty (1980a, 1980b, 1982, 1992), and Driskill, Mark, and Sheffrin (1987).
} 
fourth and fifth terms show that the exchange rate is influenced by the level and the change in interest differentials: not surprisingly, a rise in domestic interest rates (a positive $\eta_{t+1}$ ) immediately depreciates the foreign currency. The coefficient on the current interest differential is positive because, with mean reversion, a high current interest-rate differential means declining differentials over the future. Thus speculators will be planning concurrent decreases in their holdings of foreign exchange. The effect is stronger when mean reversion occurs more rapidly.

The introduction of speculators transforms short-run exchange-rate dynamics. When speculators are absent the exchange rate always satisfies $s_{t}=C_{t} / K=\left(\bar{C}+\varepsilon_{t}\right) / K$, so interest differentials have no effect on exchange rates. By contrast, when speculators are present both the level and the change in interest differentials affect current exchange rates. When speculators are absent any nonzero shock to commercial demand, $\varepsilon_{t}$, is immediately and fully reflected in the current exchange rate and has no impact thereafter; thus the exchange rate would be i.i.d. under the current specification. When speculators are present the exchange rate's response to a $\varepsilon$-shock is initially muted and lasts indefinitely (Osler 1998).

Understanding the way speculators transform the effects of commercial shocks is helpful for understanding how the model as a whole fits many of the major macro empirical regularities, so we pause to provide an illustration. Suppose that the exchange rate is at long-run equilibrium and the interest differential is zero. Now add a positive shock to commercial demand, $\varepsilon_{t}>0$. In the absence of speculators the exchange rate would rise in period $t$ by $\varepsilon_{t} / K$. It would then be expected to decline back to its long-run level, since the expected value of future current-account shocks is zero and each shock lasts just one period. Now add just one speculator. In period $t$ that speculator rationally recognizes that the rate is likely to decline between $t$ and $t+1$, and therefore he sells foreign currency. This sale reduces the initial upward impact of the commercial shock in period $t$ itself. In deciding how much to sell the speculator recognizes that in the next period he will likely unwind some of his initial position in order to reap his profits, pushing the $t+1$ price upwards relative to its long-run equilibrium.

In full rational expectations equilibrium the speculator will hold short positions of declining magnitude over time. The aggregate impact of the commercial-demand shock remains $\varepsilon_{l} / K$ but this 
impact is redistributed: the initial impact is smaller that it would be without speculators, but later effects are larger. ${ }^{14}$ The influence of speculators on exchange rates is summarized by the variable $\lambda$, which is monotonically related to speculative activity, given the statistical distributions of shocks. As $\lambda$ rises the influence of speculators on exchange-rate behavior intensifies.

\section{Equilibrium and the Macroeconomics Evidence}

The preceding discussion provides a useful framework for understanding how this model fits many of the puzzling anomalies from international macroeconomics. The key insight concerns the way speculators transform the influence of shocks: in the absence of speculators a one-period shock has a one-period effect; when speculators are present that same total effect is distributed more evenly across time. With sufficient speculators the effect will be distributed so evenly that an econometrician would conclude that the exchange rate follows a random walk. This explains why the model is consistent with the exchange-rate disconnect puzzle (Osler 1998).

The model can also explain why exchange-rate volatility rose under floating exchange rates even while the volatility of fundamentals remained unchanged (Flood and Rose 1995). When exchange rates began to float it became feasible for speculators to make substantial amounts of money. Speculators tend to reduce any volatility introduced by real-side shocks, but they also introduce new sources of volatility that were not important under fixed rates: interest rates and news. As shown with an earlier version of this model, rational speculators can increase in volatility, rather than reduce it as predicted by Friedman (1953), if there are enough of them (Carlson and Osler 2000).

The model predicts that relative prices dominate exchange rates in the long run but do not dominate in the short run - intuitively, the model can explain why PPP fails at short horizons but succeeds at long horizons (Rogoff 1996). In our model, commercial traders help bring exchange rates into line with a competitive long-run equilibrium by shifting their purchasing patterns in response to changes in the terms of trade. In the short run, speculators also influence the exchange rate, and can sometimes drive it away from long-run equilibrium. In the long run, though, speculators are neutral because they ultimately unwind every position in order to reap their profits. Intuitively, any

${ }^{14}$ This analysis is further elaborated in Osler (1998) and Carlson and Osler (2000). 
purchase's upward push to the exchange rate will ultimately be associated with a corresponding downward push when the position is unwound. Thus commercial traders, and a condition analogous to PPP, dominate long-run but not short-run exchange rates. Note that, given the long-run influence of money on prices, this also implies that our model's long-run equilibrium is consistent with the monetary model (Mussa 1976) and the intertemporal optimizing model of Obstfeld and Rogoff (1995, 2003).

\section{Risk Premiums and Interest Parity}

This section of the paper shows that our microstructure-consistent model is also consistent with three familiar macro-level anomalies: the volatility and persistence puzzles and the failure of UIP. Since these all concern foreign exchange risk premiums, we now analyze the model's risk premiums more closely.

Risk premiums in the model vary across time and are strongly influenced by interest differentials, consistent with the empirical evidence. Further, risk premiums are unlikely to be driven to zero by competition among market participants. When we enhance the model by adding a permanent component to real-side shocks and by making commercial trading sensitive to interest rates we find that exchange-rate changes and interest differentials can be negatively related, consistent with the forward premium puzzle.

\section{A. Risk Premiums}

The expected exchange-rate change, derived from Equation (8), is: $E_{t} s_{t+1}-s_{t}=(1-\lambda)\left(\bar{s}-s_{t}\right)$ $+\beta d_{t} \quad$, where $0<\beta=\lambda(1-\rho) /(1-\rho \lambda)<1$. Thus the risk premium is

$$
r p_{t} \equiv E_{t} s_{t+1}-s_{t}-d_{t}=(1-\lambda)\left(\bar{s}-s_{t}\right)+(\beta-1) d_{t}
$$

So long as $\lambda<1$, the model predicts that the risk premium varies over time and is determined by the gap between current and long-run exchange rates, which we call the "exchange-rate gap," and by the interest differential. Other factors affect the risk premium through $\lambda$ and $\beta$. These include the extent of commercial activity, the number of speculators, speculators' risk aversion, the volatility of the underlying shocks, and the autocorrelation of interest differentials. 
The connection between risk premiums and the exchange-rate gap can best be explained with an example. Suppose that the interest differential is fixed at zero, and that the exchange rate is below its long-run value. Speculators would choose to hold a long position in foreign currency so long as they could expect some compensation for the associated risk. In equilibrium, a larger exchange-rate gap is associated with a larger open currency position and higher expected compensation for risk.

The importance of portfolio allocations for risk also explains the relationship between risk premiums and interest differentials. Once again, an example may clarify the intuition. Suppose dollar interest rates rise relative to interest rates on assets denominated in other currencies, as they did in the early 1980s. Other things equal, foreign speculators will choose to own more dollar assets, and thus increase their exposure to currency risk. In equilibrium, a larger risk premium on dollars will be required to compensate speculators for their increased exposure.

This discussion makes clear that the risk relevant for risk premiums in this model does not arise exclusively from exchange-rate volatility. Risk also depends on the size of short-term speculative positions. As the example suggests, this interpretation of risk could be useful in understanding the dollar's behavior in the early 1980s. The risk premiums of that era may not have been the associated with the general economic risk relevant to the "safe haven" hypothesis cited by Froot and Thaler (1990); instead, it could have been position risk, as foreign agents accumulated everlarger exposure to dollar-denominated assets in response to relatively attractive returns in the U.S. That is, the causation may have run from interest differentials to speculative positions to risk premiums. (See Goodhart 1988 and Carlson 1998 for further discussion of this view.)

\section{B. Interest Parity}

If speculators were extremely active, $\lambda$ would be close to unity, risk premiums would be tiny, and the model would conform approximately to uncovered interest parity. However, $\lambda$ will almost certainly not reach unity because foreign exchange speculation is naturally limited by competition from other markets. We model this point explicitly below, following Osler (1995).

We endogenize speculative activity by assuming that financial agents - or more accurately, their employers - compare unconditional expected welfare from trading in the market, $E\left(W_{t}\right)$, with an 
exogenous benchmark denoted $W^{*}$. We model the participation choice with respect to unconditional expected welfare because, in reality, the participation choice is made on a low-frequency basis perhaps once each year - while a single period in the model corresponds to a shorter time frame, anywhere between a day and a quarter. $W^{*}$ can summarize the large fixed costs associated with financial traders: training them, providing them space and real-time information, and paying their base salaries. Alternatively, $W^{*}$ can represent expected welfare from speculating in other markets or any other use of the relevant resources. ${ }^{15}$ If $E\left(W_{t}\right)$ is greater than $W^{*}$, then other firms/people have an incentive to engage in foreign exchange speculation; conversely, if $E\left(W_{t}\right)$ is less than $W^{*}$ some currency speculators will drop out. Thus the number of speculators, $N$, is endogenous.

Unconditional expected welfare, based on Equation (2), depends on the extent of speculative activity, $\lambda$, risk aversion, $\theta$, and parameters governing the behavior of shocks: $\operatorname{Var}(\varepsilon), \operatorname{Var}(\eta)$, and $\rho$ :

$$
E\left(W_{t}\right)=\frac{(1-\lambda)^{3}}{2 \theta(1+\lambda)}\left[\frac{\operatorname{var}(\varepsilon)}{\operatorname{var}(v)}+\frac{(1+\rho \lambda)}{(1-\rho \lambda)^{3}\left(1-\rho^{2}\right)} \frac{\operatorname{var}(\eta)}{\operatorname{var}(v)}\right]
$$

(see Appendix for details). The implications of Equation (10) for speculative activity are not immediately obvious because the relationship between unconditional welfare and $\lambda$, or equivalently between unconditional welfare and the amount of speculative activity, is not necessarily monotonic. By way of illustration, Figure 2 depicts $E\left(W_{t}\right)$ as a function of $\lambda^{16}$

A stable equilibrium occurs when $E(W)$ cuts $W^{*}$ from above. This condition must be satisfied at least once within the space since, as can be inferred from Equation (10), unconditional expected welfare becomes arbitrarily small for large values of $\lambda$. If $E(W)$ is greater than $W^{*}$ there is an incentive for additional speculators to enter the market, so $N$ and hence $\lambda$ increase. If $E(W)$ is less than $W^{*}$ there is an incentive for speculators to drop out so $N$ decreases. To illustrate that the equilibrium number of speculators will be finite, Figure 3 depicts a mapping from values of $W^{*}$ to the number of speculators $N$ (parameters for these solutions are as for Figure 2 plus $S=100$ ). For lower values of

\footnotetext{
${ }^{15}$ If $W^{*}$ is taken to be an opportunity cost of speculating, we assume that it is bounded away from arbitrarily low levels. If one restricts the relevant "alternative activities" to asset market speculation, then there must be some finite limit to the total possible amount of speculation; this seems reasonable.

${ }^{16}$ These parameters are consistent with those used in simulations reported below. If the coefficient of risk aversion $\theta$ were larger, $E(W)$ would be lower in Figure 2, and the equilibrium value for $\lambda$ would also be lower.
} 
$W^{*}$, there will be more speculators, but the number approaches infinity only when $W^{*}$ approaches zero. In equilibrium - that is, when $E\left(W_{t}\right)=W^{*}$ - there is no incentive for additional speculators to enter the foreign exchange market. Equilibrium speculation is finite, equilibrium values of $\lambda$ are bounded away from unity, and there is no presumption that UIP holds even approximately.

\section{Permanent Shocks}

In reality, commercial currency demand is subject to permanent as well as transitory shifts. Among the potential sources of such shifts, the maximizing framework of Section 1 highlights nominal prices and economic activity (represented by $K$, the number of firms). As shown in the Appendix, when the commercial demand shocks have permanent and transitory components the exchange-rate change is:

(11) $s_{t+1}-s_{t}=\left(E_{t+1} \bar{s}_{t+2}-E_{t} \bar{s}_{t+1}\right)+(1-\lambda)\left(E_{t} \bar{s}_{t+1}-s_{t}\right)+\beta d_{t}+(1-\lambda) \varepsilon_{t+1}-\frac{\lambda}{1-\rho \lambda} \eta_{t+1} .$.

Here, $\beta, \rho$, and $\lambda$ are defined as before. The term $E_{t} \bar{s}_{t+l}$ represents the expectation, based on information available at time $t$, of the exchange rate that would be reached in the long run if fundamental variables remained constant at their time- $t$ values. For brevity we still refer to $\bar{S}_{t}$ as the long-run equilibrium exchange-rate. The risk premium is:

$$
r p_{t}=\left(E_{t} \bar{s}_{t+2}-E_{t} \bar{s}_{t+1}\right)+(1-\lambda)\left(E_{t} \bar{s}_{t+1}-s_{t}\right)+(\beta-1) d_{t},
$$

where we use the law of iterative expectations to express $E_{t} E_{t+1} \bar{S}_{t+2}$ as $E_{t} \bar{S}_{t+2}$.

Equations (11) and (12) show that exchange-rate changes and risk premiums are still affected by the exchange-rate gap and the interest differential. However, they are now also influenced by the anticipated change in the long-run equilibrium rate. Any change in the long-run rate is immediately reflected in the current exchange rate, consistent with standard depictions of efficient markets.

In any case, the forward premium puzzle may no longer exist. The relationship between interest differentials and risk premiums is positive when interest differentials are very large, as shown by Flood and Taylor (1996), and when assets have long maturities (Chinn and Meredith 2004). Even short-run risk premiums among low-interest-rate countries seem to have been positively related to 
interest differentials during the 1990s (Baillie and Bollerslev 2000, Flood and Rose 2002). Sarno et al. (2004) goes further, suggesting that the negative relationship was never economically meaningful.

They show that, historically, when a negative relationship prevailed expected profits from speculating were typically small - smaller than transactions costs, in fact. When a positive relationship prevailed, by contrast, expected speculative profits were substantial and the profitable trading opportunity disappeared quickly. As noted earlier, our baseline model is also consistent with a positive relationship between interest differentials and exchange-rate changes.

\section{Matching The Evidence: Calibrated Simulations}

In this section we use calibrated simulations to show that our model fits a key empirical regularity from microstructure as well as various macro puzzles, specifically the volatility and persistence puzzles. It also predicts the failure of UIP, though not the magnitude of that failure.

\section{A. Calibrated Simulations}

The model to be simulated comprises Equation (15) in the text with $\bar{E}_{t} \bar{s}_{t+1}=E_{t} C_{t+1} / K$. Each simulation involves a set of parameters and a set of initial values for the state variables $\underline{s}_{0}, d_{0}, \mathrm{C}_{0}$, $E_{0} \bar{s}_{1}, E_{0} \bar{s}_{2}$. For each of 10,000 periods we draw values from normal distributions for $\varepsilon$ and $\eta$ to generate new values for $s, d$, and $C$.

The exogenous parameters are: $\rho, \sigma_{\eta}^{2}, \sigma_{s}^{2}, \gamma$ (defined below), $\lambda$, and $I / K$. Whenever possible, baseline values of these parameters are chosen to correspond with corresponding properties of five dollar exchange rates against the Deutschemark/euro, yen, pound, Swiss franc, and Canadian dollar. The autocorrelation of interest differentials, $\rho$, and the variance of interest-differential shocks, $\sigma_{\eta}^{2}$ match, roughly, corresponding figures for quarterly differentials between U.S. three-month euro rates and those of Germany, Japan, Switzerland, the U.K., and Canada. The observed autocorrelation averages 0.89 (1970-2004 for Germany, Switzerland, and the U.K.; 1978-2004 for Japan and Canada); the observed standard deviation of $\eta$ averages 0.342 .

The assumed quarterly standard deviation of exchange-rate returns, $\sigma_{s}$, is the average quarterly standard deviation of our five exchange rates, 5.4 percent. Since exchange-rate dynamics are 
endogenous, this constrains the feasible combinations of $\sigma_{\varepsilon}^{2}$ and $\gamma$ given the other parameters. The shock to commercial demand includes both permanent and transitory components. In moving-average form the commercial demand intercept is: $C_{t}=C_{t-1}+\varepsilon_{t}-\gamma \varepsilon_{t-1}$. The transitory fraction of the shock, $\gamma$, is initially set at 0.5 . Other things equal, $\sigma_{s}^{2}$ rises with $\gamma$.

Without loss of generality we summarize the influence of speculator activity (determined by their risk aversion, $\theta$, their number, $N$, and other factors) in an exogenous value of $\lambda$. Estimates of $\lambda$, presented in Section V, suggest that it is about 0.9 and perhaps higher. ${ }^{17}$ Good estimates of the ratio $I / K$ do not exist, so we experiment with a variety of values.

\section{The Microstructure Evidence}

We begin by showing that commercial agents in our model will be net liquidity suppliers to financial agents, on average, for our baseline parameterization of the model and for most substantial variants. In this way the model predicts one of the key stylized facts from currency microstructure.

We focus in particular on the volatility of the model's exogenous shocks, based on the following thought experiment. Suppose that goods markets are not subject to exogenous shocks, so that interest rates provide the only exchange-rate shocks, and the foreign interest rate rises. Financial traders will wish to purchase more foreign currency. However, they cannot do so until commercial firms are induced to sell foreign currency, and this requires a higher exchange rate. In this case, financial (commercial) demand is positively (negatively) related to the exchange-rate return, consistent with the microstructure evidence. After the initial shock, commercial traders will continue to provide liquidity to financial traders as financial traders slowly unwind their positions.

Alternatively, suppose that commercial demand is subject to a positive shock $\left(\varepsilon_{t}>0\right)$ while interest rates are constant $\left(d_{t} \equiv d, \Delta \equiv 0\right)$. Commercial traders will want to purchase more foreign currency, which cannot happen until the exchange rate rises, reducing expected returns and generating some financial supply. In this case, financial (commercial) demand will initially fall (rise) while the value of foreign currency rises, in opposition to the microstructure evidence that financial

\footnotetext{
${ }^{17}$ Though $\lambda$ is not a parameter, it is closely related to the parameter $W$, and it is technically more straightforward to solve for equilibrium when varying $\lambda$ than $W$.*
} 
(commercial) order flow is positively (negatively) related to exchange rates. Thereafter, however, commercial traders will again be liquidity providers as financial traders unwind their positions.

This intuitive analysis suggests that commercial traders are liquidity demanders only as an immediate response to commercial-demand shocks. Financial traders, by contrast, are liquidity demanders as an immediate response to interest-rate shocks but also in the aftermath of any shock. Together, this implies that commercial traders will tend to be liquidity providers, on average, but will do so somewhat less when commercial demand shocks are prominent relative to interest-rate shocks.

The simulations support these inferences. If the volatility of interest-differential shocks is 0.342 , and the volatility of commercial-demand shocks is 8.42 - a combination that generates the required exchange-rate volatility of 5.4, together with our other baseline parameters - the correlation between commercial demand and returns is -0.025 , as shown in the second row and last column of Table 1. In this baseline simulation, we assume that interest rate shifts are the only source of shocks to financial demand and that all the residual shocks necessary to match exchange rate volatility comes from commercial agents. The last three columns of Table 1 show the effects of reducing the volatility of commercial demand shocks and increasing shocks to financial demand, again maintaining a constant level of exchange-rate volatility. As predicted, the correlation between commercial demand and exchange-rate shocks becomes increasingly negative.

\section{The Macroeconomic Evidence}

We next show that the model can conform to the volatility and persistence puzzles and the failure of UIP. Macro-based models that try to replicate these three stylized facts (e.g., Bekaert 1996, Moore and Roche 2002) have been unable to match at least one. We analyze the model's performance on these anomalies for the base case as well as for various simulations (see Table 1).

Volatility puzzle: Consistent with the volatility puzzle, the standard deviation of exchange-rate changes in our model greatly exceeds the standard deviations of both risk premiums and interest 
differentials. ${ }^{18}$ Indeed, the standard deviation of risk premiums never rises to twenty percent of the standard deviation of exchange-rate changes.

Persistence puzzle: Consistent with the persistence puzzle, the autocorrelation of exchangerate changes in our model is close to zero even though the autocorrelation of interest differentials is consistently at or above 0.90 . The small negative signs for these simulated exchange-rate autocorrelations conform to the negative-but-small quarterly autocorrelations for the Canadian Dollar/U.S. dollar and the U.K. Pound/U.S. dollar exchange rates over recent decades (-0.09 and 0.13 , respectively).

Failure of UIP: Clearly UIP does not hold in the model, since the parameter $\beta$ is not only less than unity it is consistently below 0.5 . According to the "forward premium puzzle," however, $\beta$ should be negative. It would be fairly straightforward to modify this flexible model sufficiently to generate negative $\beta$. Gruen and Gizycky (1993) find a negative relationship when some agents anchor exchange-rate expectations to current exchange rates and interest differentials. This condition seems plausible given the well-documented importance of anchoring in normal human cognitive functioning (Yates 1988) and the well-known absence of reliable models for short-run exchange-rate forecasts.

Burnside et al. (2007) provide a model of the failure of UIP based on insights from equitymarket microstructure (Glosten and Milgrom 1985, Kyle 1985). Unfortunately, the equity-market structure assumed in their model does not apply to the foreign exchange market (Osler 2008, Osler et al. 2008) and the actual behavior of foreign exchange spreads, which is critical to the analysis of Burnside et al. (2007), is inconsistent with the behavior assumed by their model.

\section{B. Portfolio Balance Models and Risk Premiums}

Our model's explanation for the behavior of risk premiums is based on the direct relationship between risk premiums and financial traders' optimal asset positions (Equation (3)). Thus the model

\footnotetext{
${ }^{18}$ Note that our results are also consistent with Bakaert's condition that his estimated lower bound for the volatility of risk premiums $\sigma\left(d_{t}\right)|\beta-1|$, exceeds the volatility of interest differentials. This condition is satisfied whenever whenever $|\beta-1|>1$, which is true in all our simulations. However, his estimation approach implicitly assumes that changes in interest differentials have only one, direct connection to risk premiums, an assumption that is not correct according to our model. The indirect connection works through the unconditional negative covariance between the interest-rate differential and the exchange-rate gap (see equation (A.29) in the appendix).
} 
implies that the highly variable risk premiums of reality must be accompanied by highly variable international net asset positions. Since portfolio balance models assume investors essentially identical to the ones modeled here, it seems logical that the same conclusion arises from portfolio balance models. Historically, however, this explanation has been considered inadequate to explain the behavior of currency risk premiums. We suggest that this negative view involved a key oversight.

As Lewis (1995) notes, in traditional portfolio balance models

the sign of the risk premium would [also] depend on the difference between ... domestic holdings of foreign bonds and foreign holdings of domestic bonds. When domestic residents are net creditors ... then the overall effect on the risk premium is to compensate domestic investors for net holdings of foreign deposits.... [I]nfrequent shifts between net debtor to creditor positions ... suggest that this model cannot explain the changes in sign in predictable returns (pp. 1926-1927).

Indeed, the U.S. overall net asset position has changed sign just once over the past three decades.

Lewis's (1995) rejection of the portfolio balance explanation for risk premiums implicitly assumes that a country's overall net international asset position is the relevant measure of international asset holdings. But overall net asset positions include assets that are generally held for long periods, such as foreign direct investment and international loans. Indeed, long-term assets can dominate net asset positions. In 2001, for example, positions in long-term assets accounted for at least two-thirds of U.S. asset holdings abroad and 60 percent of foreign asset holdings in the U.S. (at market value). ${ }^{19}$

The empirical analysis of risk premiums, however, has focused almost entirely on assets with maturity ranging from one week to one year. Long-run investments are unlikely to be sensitive to the short-term risk premiums, so the lack of any relationship between short-run risk premiums and international asset positions may be logical rather than surprising. The international asset positions relevant to short-term risk premiums should presumably be related to short-run positions, such as short-term time deposits and high-turnover stock and bond holdings. Such short-term accounts are the very ones on which our model focuses.

\footnotetext{
${ }^{19}$ To arrive at this figure, long-term holdings were taken to be official reserve assets, other government assets, foreign direct investment, claims reported by non-banking concerns, and claims "reported by banks not included elsewhere."
} 
Though data are not available on holdings of short-term assets, we note that net open positions of large speculative futures traders change sign a few times per year. Weekly data from the International Money Market over the period January 1993 through May 2003 show that these traders' net open position changed sign 75 times for U.K. Pound contracts, or on average 7.2 times per year. Comparable yearly average figures for other currencies are: 5.1 for Swiss Franc contracts, 3.7 for yen contracts, 9.1 for DEM contracts, and 4.3 for Euro contracts. ${ }^{20}$ That these observations, together with the results of our calibrated simulations, hopefully re-open the possibility that portfolio-balance factors could help explain short-term currency risk premiums.

\section{REGRESSION ANALYSIS}

Our linear solution for the exchange-rate risk premium (Equations 12 or 15) lends itself naturally to regression tests. Using quarterly data for five major currencies versus the U.S. dollar we find that our microstructure-based model fits reasonably well.

\section{A. Traditional Risk Premium Regressions}

First, we replicate a version of the standard regression in the literature:

$$
x r_{t+1}=\alpha+\psi d_{t}+\xi_{t+1} .
$$

We estimate this expression using quarterly data on five exchange rates - DEM/EUR, JPY, CHF, GBP, and CAD - and corresponding three-month eurocurrency interest rates over January, 1973, through June, 2003. As shown in Table 2, OLS estimates of Equation (16) produce estimates of $\gamma$ that are consistently negative, greater than unity in absolute value, and highly statistically significant. The explanatory power is fairly low, with adjusted $R^{2}$ s averaging only 0.10 . All of this is consistent with earlier studies.

\section{B. Regressions Based on our Theoretical Model}

In our model the excess return to currency can be expressed as follows:

$$
x r_{t+1}=\left(E_{t+1} \bar{s}_{t+2}-E_{t} \bar{s}_{t+1}\right)+(1-\lambda)\left(E_{t} \bar{s}_{t+1}-s_{t}\right)+(\beta-1) d_{t}+v_{t+1},
$$

\footnotetext{
${ }^{20}$ We are grateful to Thomas Klitgaard, Federal Reserve Bank of New York, for providing these data.
} 
where $v_{t+1} \equiv(1-\lambda) \varepsilon_{t+1}-\frac{\lambda}{1-\rho \lambda} \eta_{t+1}$ is i.i.d. with mean zero. Thus, our model suggests that the standard regression is mis-specified due to the exclusion of two variables, the change in the expected long-run equilibrium exchange rate and the exchange-rate gap.

Our estimating equation, based on Equation (17), is then given as

$$
x r_{t+1}=\alpha+\delta\left(E_{t+1} \bar{S}_{t+2}-E_{t} \bar{s}_{t+1}\right)+(1-\lambda)\left(E_{t} \bar{s}_{t+1}-s_{t}\right)+(\beta-1) d_{t}+\mathrm{v}_{t+1}
$$

where the parameters of interest are $\Theta=(\alpha, \delta, \lambda, \beta)^{\prime}$. According to the model, the constant term, $\alpha$, should be zero and the coefficient on the change-in-expected-long-run exchange rate, $\delta$, should be unity. The model also implies that $(1-\lambda)$ represents the speed with which the exchange rate responds to deviations from the long-run terms of trade (or, informally, the speed of adjustment to PPP), and thus this parameter should be between zero and one. Finally, $(\beta-1)$ should be between zero and negative one.

Since $E_{t+1} \bar{S}_{t+2}$ and $E_{t} \bar{S}_{t+1}$ are unobserved random variables, it is not possible to estimate $\Theta$ based on Equation (15) without imposing additional restrictions. Based on our earlier model of commercial demand we assume the long-run exchange rate is determined by PPP (or its analogue in the context of the terms of trade), which implies that the long-run equilibrium terms of trade is constant at $M$. This implies that the long-run-consistent nominal exchange rate, $\bar{s}_{t}$, satisfies $\bar{s}_{t}=M+$ $p_{t}-p_{t}^{*}$ (we use log producer price indexes for $p_{t}$ and $p_{t}{ }^{*}$ ). We assume that domestic and foreign prices are determined only by their own past values:

$$
\begin{aligned}
& p_{t}=\Pi_{t-1}^{\prime} \gamma_{0}+\varepsilon_{1 t} \\
& p_{t}^{*}=\Pi_{t-1}^{*} \gamma_{1}+\varepsilon_{2 t}
\end{aligned}
$$

where $\Pi_{t} \equiv\left(1, p_{t}, \ldots, p_{t-s}\right)^{\prime}, \Pi^{*}{ }_{t} \equiv\left(1, p_{t}{ }^{*}, \ldots, p_{t-s^{*}}{ }^{*}\right)^{\prime}$. Define $\varepsilon_{t} \equiv\left(\varepsilon_{1 t}, \varepsilon_{2 t}\right)^{\prime}$ with $E_{t} \varepsilon_{t}=0$. We can now write

$$
\bar{s}_{t} \quad=M+p_{t}-p_{t}^{*}=M+\Pi_{t-1} \gamma_{0}-\Pi_{t-1}^{*} \gamma_{1}+n_{t}
$$

such that

$$
E_{t} \bar{s}_{t+1}=M+\Pi_{t}^{\prime} \gamma_{0}-\Pi_{t}^{*}{ }_{t}^{\prime} \gamma_{1} \quad \text { and } \quad E_{t+1} \bar{s}_{t+2}=M+\Pi_{t+1} \gamma_{0}-\Pi^{*}{ }_{t+1}^{\prime} \gamma_{1} .
$$


With this, we redefine the second and third right-hand-side variables of Equation (15) as follows:

$$
E_{t+1} \bar{S}_{t+2}-E_{t} \bar{s}_{t+1}=\Delta \Pi_{t+1} \gamma_{0}-\Delta \Pi_{t+1}^{*} \gamma_{1}
$$

where $\Delta \Pi_{t}=\left(\Delta p_{t}, \ldots, \Delta p_{t-s}\right)^{\prime}$ and $\Delta \Pi^{*}{ }_{t}$ is defined similarly, and

$$
E_{t} \bar{s}_{t+1}-\mathrm{S}_{\mathrm{t}} \quad=M+\Pi_{t}^{\prime} \gamma_{0}-\Pi_{t}^{*}{ }_{t}^{\prime} \gamma_{1}-s_{t}
$$

We adopt two estimation approaches, described below. The first directly estimates the parameters of interest using quasi-maximum likelihood. The second uses a two-step procedure to estimate the parameters.

1. One-Step Estimation by Quasi Maximum Likelihood.

Inserting Equations (20) and (21) into (15) gives

$$
x r_{t+1}=\alpha+\delta\left(\Delta \Pi_{t+1} \gamma_{0}-\Delta \Pi^{*}{ }_{t+1}^{\prime} \gamma_{1}\right)+(1-\lambda)\left(M+\Pi_{t}^{\prime} \gamma_{0}-\Pi^{*}{ }_{t}^{\prime} \gamma_{1}-s_{t}\right)+(\beta-1) d_{t}+\mathrm{v}_{t+1} \quad .
$$

Consistent estimation of coefficients and their standard errors is straightforward in the classical likelihood framework under the reasonable assumptions that the dependent variable and the regressors are all stationary and so long as $v_{t+1}$ is independent of the regressors. We maintain the stationarity assumptions, and use Hausman's (1978) test to determine whether the regressors, in particular $p_{t+l}$ and $p_{t+1} *$, are exogenous with respect to the parameters of interest. If they are not, we adopt the two-stage procedure described below. Furthermore, we test for time dependence of $v_{t+1}$ (AR-effects) as well as in its conditional variance (ARCH-effects) using the classical as well as the robust Lagrange Mulitplier test as suggested by Wooldridge (1991) and the well known Ljung-Box test. If it appears that we have neglected AR of ARCH effects we augment the model with lagged values of $x r_{t+1}$ and/or increase the dimension of $\Pi_{t}$ and $\Pi_{t}^{*}$ respectively.

\section{Two-step Estimation}

In some cases the Hausman test indicates that it is unreasonable to assume that $p_{t+1}$ and $p_{t+1} *$, are independent with respect to $\mathrm{v}_{t+1}$. Following standard practice in time series analysis, we use lagged prices $\left(\Pi_{t}\right.$ and $\Pi_{t}^{*}$, respectively), as instruments. This implies the following two-stage estimation procedure.

Step 1: Approximate the second term in Equation (15), $\left(E_{t+1} \bar{s}_{t+2}-E_{t} \bar{s}_{t+1}\right)$, as follows 


$$
\left(E_{t+1} \bar{s}_{t+2}-E_{t} \bar{s}_{t+1}\right)=\left(E_{t+1} p_{t+2}-E_{t} p_{t+1}\right)-\left(E_{t+1} p_{t+2} *_{-} E_{t} p_{t+1} *\right)+\zeta_{t} \text {, by }
$$

$\Delta \hat{p}_{t+2}-\Delta \hat{p}_{t+2} * \quad$, where

$$
\Delta \hat{p}_{t+2}=\Delta \Pi^{\prime}{ }_{t} \hat{\gamma}_{o} \quad,
$$$$
\Delta \hat{p}_{t+2} * \Delta \Pi_{t}^{\prime} * \hat{\gamma}_{1} \quad,
$$

and $\hat{\gamma}_{o}$ and $\hat{\gamma}_{1}$ are obtained from regression of $\Delta p_{t}$ and $\Delta p_{t}{ }^{*}$ on a constant and $\Delta \Pi_{t-2}$ and $\Delta \Pi_{t-2}{ }^{*}$ respectively. Similarly, we replace the second term in expression (16), the exchange-rate gap:

$$
\begin{aligned}
& E_{t} \bar{s}_{t+1}-s_{t}=M+E_{t} p_{t+1}-E_{t} p_{t+1} *-s_{t} \quad \text {, with } \\
& \hat{\mathrm{E}}_{\mathrm{t}} p_{t+1} \equiv \hat{p}_{t+1}=\Pi_{t}{ }^{\prime} \hat{\phi}_{0}, \\
& \hat{\mathrm{E}}_{\mathrm{t}} p_{t+1} * \equiv \hat{p}_{t+1} *=\Pi_{t} * \hat{\phi}_{1} \quad \text {, where } \hat{\phi}_{0} \text { and } \hat{\phi}_{1} \text { are obtained from the }
\end{aligned}
$$

regressions of $p_{t}$ and $p_{t}{ }^{*}$ on a constant and $\Pi_{t-1}$ and $\Pi_{t-1^{*}}$ respectively.

Step 2: Estimate $\Theta=(\alpha, \delta, \lambda, \beta)^{\prime}$ by maximum likelihood estimation from the representation

$$
x r_{t+1}=\alpha+\delta\left(\Delta \hat{p}_{t+2}-\Delta \hat{p}_{t+2} *\right)+(1-\lambda)\left(M+\hat{p}_{t+1}-\hat{p}_{t+1}-s_{t}\right)+(1-\beta) d_{t}+v_{t+1} .
$$

Denote the estimate $\hat{\Theta}$. To compute the variance-covariance matrix of the two-step estimator we use the formula provided by Murphy and Topel (1985). This regression is consistent under the same conditions highlighted above: the dependent variable and the regressors must all be stationary and $\mathrm{v}_{t+1}$ must be independent of the regressors. Stationarity is once again assumed. To remove neglected AR and ARCH effects we augment the model with lagged values of $x r_{t+1}$ or increase $s / s^{*}$, in order. Note that $\alpha$ is unidentified, as in the ML approach, and we therefore cannot use the estimated constant term to draw conclusion regarding the appropriateness of the theoretical model.

The estimates of our key estimating equation, shown as Equation (15), as well as the battery of diagnostics discussed above are reported in Table 3. The ML estimates should be preferred over the ML-2S estimators due to better efficiency properties, so long as they are properly specified and there is no neglected endogeneity. However, for two countries, the United Kingdom and Japan, strong evidence of neglected endogeneity emerges from the Hausman test statistic. Thus we focus on the ML-2S approach for these two countries and the ML estimates for the remaining three countries. 
The diagnostic tests suggest that the models are generally well specified: there are indications of neglected ARCH in the estimated models for United Kingdom, Germany and Canada at the five percent level but no significant ARCH effects anywhere at the one percent level. Furthermore, the classical likelihood ratio test indicates that the goodness of fit is consistently higher than that of the standard regressions. Hence, the standard risk premium equation can be rejected as empirically misspecified in favor of our own model-based regressions.

The estimated coefficients on the interest differential, $\beta$, are negative as expected and the estimates of $\beta-1$ are in most cases of similar magnitude as the $\psi$ estimates reported for the standard excess-return regressions in Table 2. While all of the point estimates exceed one in absolute value, the differences are not statistically significant in most cases.

The coefficients on the exchange-rate gap, $\lambda$, all have the theoretically expected positive sign and economically sensible magnitudes. They imply that between four and twelve percent of any deviation from PPP is eliminated per quarter, and that the real-exchange-rate half-life ranges between sixteen months and three years. This figure is between Rogoff's (1996) "consensus view" of three to five years and the alternative, and perhaps more accurate, value of fourteen months found in Imbs $e t$ al.'s (2002) analysis of disaggregated data. Imbs et al. shows that estimated half-lives will be biased upwards when measured with aggregate data, and we are constrained to use such data. Thus our estimated average half-life will naturally exceed fourteen months due to aggregation bias.

Note that all the exchange-rate gap coefficients are statistically significant at the five percent level. By contrast, economists usually encounter great difficulty, in datasets of this length, detecting any statistically significant convergence to PPP. This contrast is encouraging since it suggests that traditional attempts to model convergence to PPP suffered from the omission of variables suggested by our model.

As required by the model, the estimated coefficients on the change in long-run expected exchange rate, $\delta$, do not differ significantly from unity at the five percent level with the exception of Japan. Nonetheless, the estimated coefficients are typically somewhat larger than unity while for 
Japan it is negative. In general, these coefficients have large standard deviations, as might be expected since the variable is unobservable and has necessarily been estimated.

Overall, this empirical analysis supports the model's implications that realized risk premiums are endogenously determined by interest rate differentials, the gap between the exchange rate and its long-run expected value, and news.

\section{Conclusions}

This paper presents an optimizing model of short-run exchange-rate dynamics with a structure essentially dictated by new microstructure evidence concerning the structure of currency markets. The model's implications for equilibrium exchange-rate dynamics conform to additional microstructure evidence concerning the relations between order flow and returns, specifically that financial (commercial) order flow is positively (negatively) related to returns. The model also conforms to most of the major macro puzzles that have perplexed economists for decades, including the following: the short-run failure but long-run success of PPP; the exchange-rate disconnect puzzle; the increase in real exchange rate volatility upon the advent of floating rates; the volatility and persistence puzzles; and the failure of uncovered interest parity.

These assumptions have an additional difficulties worth noting, specifically the fact that they are grossly violated at short horizons. The PPP assumption, for example, requires that the influence from aggregate prices to exchange rates works intraday, but this influence works extremely slowly rather than minutes or hours it typically takes years for prices to influence exchange rates. Thus it is not clear whether anything can be learned about high-frequency returns from such models. It is certainly clear, however, that we should not expect the models to perform well when confronted with data and the models do indeed perform poorly when actually tested (e.g., Chinn and Moore 2008).

The model is intentionally streamlined, to keep the focus on exchange rates. The goal is to create a plausible framework for understanding exchange rates that can ultimately be incorporated into richer models of international macroeconomic interactions.

The model is intended to meet the basic scientific challenge articulated by Popper (1959). In his view, when evidence shows that an existing model is critically inconsistent with reality, scientists 
should develop new models that are consistent with the best evidence of the time (future evidence may show that the new models, too, are inconsistent with reality). When applied to short horizons, the dominant exchange-rate models of today are inconsistent with today's best evidence in a number of dimensions, including their assumption of continuous PPP, their assumption of continuous UIP, and their imposed irrelevance of order flow. By contrast, the model presented here is conforms to today's best evidence concerning the microeconomics of currency trading.

Our model achieves a critical goal within economics: it has "well-specified microfoundations." We find it encouraging that, at least with respect to exchange rates, a model that closely conforms to the best microeconomics evidence produces implications that closely conform to the best macoeconomics evidence. 


\section{REFERENCES}

Anderson, Torben G., Tim Bollerslev, Francis X. Diebold, and Clara Vega, "Micro Effects of Macro Announcements: Real-Time Price Discovery in Foreign Exchange," American Economic Review 93 (2003): 38-62.

Bacchetta, Phillip, and Eric van Wincoop, "Can Information Heterogeneity Explain the Exchange Rate Determination Problem?” American Economic Review 96, 2005, 552.

Baillie, R.T., and Bollerslev, Tim. "The forward Premium Anomaly is Not as Bad as You Think." Journal of International Money and Finance 19, 2000, 471-88.

Bekaert, Gaert. "The Time Variation of Risk and Return in Foreign Exchange Markets: A General Equilibrium Perspective." Review of Financial Studies 9,1996, 427-470.

Bensaid, Bernard, and DeBandt, Olivier. "Les strategies 'stop-loss': Theorie et application au contrat notionnel du matif." Annales d'Economie et de Statistique, 2000, 21-56.

Berger, Philip G., and Eli Ofek. Diversification's effect on firm value. Journal of Financial Economics 37, 1995, 39-65.

Bjønnes, Geir Høidal and Dagfinn Rime, Customer trading and information in foreign exchange markets. Working paper, Stockholm Institute for Financial Research. 2001.

Bjønnes, Geir Høidal, Dagfinn Rime, and Haakon O.Aa. Solheim,. Liquidity provision in the overnight foreign exchange market, Journal of International Money and Finance 24, 2005, 175 196.

Black, Stanley W. "The Effect of Alternative Intervention Policies on the Variability of Exchange Rates," in J.S. Bhandari, ed., Exchange Rate Management under Uncertainty, MIT Press, 1985, 72-82.

Brandt, Michael, and Kenneth Kavajecz, "Price Discovery in the U.S. Treasury Market: The Impact of Orderflow and Liquidity on the Yield Curve," Journal of Finance 59 (2005): 2623-2654.

Branson, William. "Stocks and Flows in International Monetary Analysis." In A. Ando at al. (eds.), International Aspects of Stabilization Policies, 27-50. Federal Reserve Bank of Boston.

Burnside, A. Craid, Martin Eichenbaum, Sergio Rebelo, "Understanding the Forward Premium Puzzle: A Microstructure Approach,” C.E.P.R. Discussion Papers 6399 (2007).

Cai, Jun, Yan-Leung Cheung, Raymond S.K. Lee, Michael Melvin, "Once-in-a-Generation' Yen Volatility in 1998: Fundamentals, Intervention, and Order Flow," Journal of International Money and Finance 20 (2001): 327-347.

Carlson, John A. "Risk Aversion, Foreign Exchange Speculation and Gambler's Ruin." Economica 65, August 1998, 441-453.

Carlson, John A. and Osler, Carol L. "Rational Speculators and Exchange Rate Volatility." European Economic Review 44, February 2000, 231-253.

Chinn, Menzie, and Meredith, Guy. "Testing Uncovered Interest Parity at Short and Long Horizons.”IMF Staff Papers 51, November 2004, 409-430.

Chinn, Menzie, and Michael Moore, "Private Information and a Macro Model of Exchange Rates: Evidence from a Novel Data Set," Mimeo.

Cross, Sam, 1998. "All About ... The Foreign Exchange Market in the United States," Federal Reserve Bank of New York (http://www.newyorkfed.org/education/addpub/usfxm/).

Danielsson, Jon, and Ryan Love, "Feedback Trading," Mimeo, London School of Economics, 2005.

DeRosa, David, Managing Foreign Exchange Riak: Advanced Strategies for Global Investors, Corporations, and Financial Institutions, Third Edition (2009: McGraw Hill, Inc.). 
Driskill, Robert, "Exchange-Rate Dynamics: An Empirical Investigation," Journal of Political Economy 89 (1981): 357-371.

Driskill, Robert and Stephen McCafferty, "Speculation, Rational Expectations, and Stability of the Foreign Exchange Market," Journal of International Economics 10, 1980a,: 91-102. , "Exchange-Rate Variability, Real and Monetary Shocks, and the Degree of Capital Mobility under Rational Expectations," Quarterly Journal of Economics 95, 1980b, 577-586.

"Spot and Forward Rates in a Stochastic Model of the Foreign Exchange Market," Journal of International Economics 12, 1982, 313-331.

,"Exchange-Rate Determination: An Equilibrium Approach with Imperfect Capital Substitutability," Journal of International Economics 23, 1987, 241-262.

Driskill, Robert, Nelson C. Mark, and Steven Sheffrin, "Some Evidence in Favor of a Monetary Rational Expectations Exchange-Rate Model with Imperfect Capital Substitutability. International Economic Review 33, 1992, 223-237.

Evans, Martin. “The Microstructure of Foreign Exchange Dynamics.” Georgetown University Working Paper, December 1998.

Evans, Martin, and Lyons, Richard K., "Order Flow and Exchange Rate Dynamics." Journal of Political Economy 110, February 2002, 170-180.

Evans, Martin, and Richard K.Lyons, "How is Macro News Transmitted to Exchange Rates?" NBER Working Paper 9433, 2003.

Georgetown University, 2004. , Exchange-Rate Fundamentals and Order Flow," Mimeo,

, "Meese-Rogoff Redux: Micro-Based Exchange-Rate Forecasting," NBER Working Paper 11,042, 2005.

Federal Reserve Bank of New York, "Management of Operational Risks in Foreign Exchange," 1996: http://www.newyorkfed.org/fxc/annualreports/ar1996/fxcar96ma.pdf.

Fleming, J. Marcus. "Domestic Financial Policies Under Fixed and Flexible Exchange Rates." IMF Staff Papers 9, 1962, 369-79.

Fleming, Michael, "The Round-the-Clock Market for U.S. Treasury Securities," Federal Reserve Bank of New York Economic Policy Review July 1997: 9-32.

"Measuring Treasury Market Liquidity," Federal Reserve Bank of New York Staff Reports (September) 2003: 83-108.

Flood, Robert P., and Rose, Andrew. "Fixing Exchange Rates: A Virtual Quest for Fundamentals." Journal of Monetary Economics 36, 1995, 3-37.

Flood, Robert P. and Rose, Andrew. "Uncovered Interest Parity in Crisis." IMF Staff Papers 49, 2002, 252-266.

Flood, Robert P. and Taylor, Mark P. "Exchange Rate Economics: What's Wrong with the Conventional Macro Approach?" in J.A. Frankel, G. Galli and A. Giovannini, eds. The Microstructure of Foreign Exchange Markets. University of Chicago Press, 1996, 261-294.

Foreign Exchange Committee, Guidelines for Foreign Exchange Trading Activities," 1996: http://www.newyorkfed.org/FXC/annualreports/ar1995/fxar9512.html\#risk_manage.

Foucault, T. "Order Flow Composition and Trading Costs in a Dynamic Limit Order Market." Journal of Financial Markets 2, 1999, 99-134. 
Frankel, Jeffrey A., Giampaolo Galli, Alberto Giovannini,, "Introduction," in The Microstructure of Foreign Exchange Markets, Jeffrey A. Frankel, Giampaolo Galli, Alberto Giovannini, Eds (University of Chicago Press, Chicago: 1996): 1-15.

Friedman, Milton, "The Methodology of Positive Economics," in Milton Friedman, Essays in Positive Economics (Chicago, University of Chicago Press: 1953): 3-43.

Froot, Kenneth A. and Thaler, Richard H. "Anomalies: Foreign Exchange." Journal of Economic Perspectives 4, Summer 1990, 179-192.

\section{Giddy, Ian, Textbook}

Glosten LR., Milgrom PR. 1985. Bid, ask, and transaction prices in a specialist market with heterogeneously informed traders. Journal of Financial Economics 14: 71-100.

Goodhart, Charles. "The Foreign Exchange Market: A Random Walk with a Dragging Anchor." Economica 55, November 1988, 437-60.

Goodhart, Charles and Payne, R. 1996, "Microstructural Dynamics in a Foreign Exchange Electronic Broking System," Journal of International Money and Finance 15, 829-52.

Gruen, David W. R., and Marianne C. Gizycki, "Forward Discount Bias: Is It Anchoring?" Working paper, Princeton University, Woodrow Wilson School of Public and International Affairs, 1993.

Hakala, Jurgen, and Uwe Wystup, 2002, Foreign Exchange Risk: Models, Instruments and Strategies (Risk Books).

Handa, P. and Schwartz, R. "Limit Order Trading." Journal of Finance 51, 1996, 1835-61.

Harris, Lawrence. "Optimal Dynamic Order Submission Strategies in Some Stylized Trading Problems." Financial Markets, Institutions, and Instruments 7, 1998, 1-76.

Hau, Harald, and Rey, Helene. "Order Flows, Exchange Rates and Asset Prices." Presented at the IFM meetings of the NBER summer institute, Cambridge, MA, July 10, 2002.

Hausman, J.A. "Specification Tests in Econometrics.” Econometrica, 46, 1978, 1251-1271

Hollifield, B.: Miller, R.; Sandas, P. and Slive, J. "Liquidity Supply and Demand in Limit Order Markets." Rodney White Center for Financial Research Working Paper, University of Pennsylvania, 2002.

Holthausen, Robert W.; Leftwich, Richard W. and Mayers, David. "Large-Block Transactions, the Speed of Response, and Temporary and Permanent Stock-Price Effects." Journal of Financial Economics 26, 1990, 71-95.

Imbs, Jean, Haroon Mumtaz, Morten Ravn, and Helene Rey. "PPP Strikes Back: Aggregation and the Real Exchange Rate.” NBER Working Paper No. 9372, 2002.

Jensen, M. and Meckling, W. "Theory of the Firm: Managerial Behavior, Agency Costs, and Ownership Structure.” Journal of Financial Economics 6, October 1976, 305-360.

Krueger, Anne O. Exchange-Rate Determination. Cambridge University Press, Cambridge: 1983.

Kyle, Albert S., "Continuous Auctions and Insider Trading,” Econometrica 53 (1985): 1315-1335.

Lane, Philip R. "The New Open Economy Macroeconomics: A Survey,” Journal of International Economics 54, 2001: 235-266.

Lang, Larry H.P., and Rene M. Stulz, “Tobin's q, Corporate Diversification, and Firm Performance," Journal of Political Economy 102: 1248-1280.

Lewis, Karen K. "Puzzles in International Financial Markets," in G. Grossman and K. Rogoff, eds., Handbook of International Economics, Vol. III, Elsevier Science, 1995, 1913-1971.

Lyons, Richard. "Tests of Microstructural Hypotheses in the Foreign Exchange Market," Journal of Financial Economics 39, 1995, 321-51. 
Lyons, Richard K. The Microstructure Approach to Exchange Rates. MIT Press, 2001.

Madhavan, Ananth, Matthew Richardson, and Mark Roomans, "Why Do Security Prices Change? A Transaction-Level Analysis of NYSE Stocks," Review of Financial Studies 10: 1035-1064.

Mark, Nelson and Wu, Yangru "Rethinking Deviations From Uncovered Interest Parity: The Role of Covariance Risk and Noise." Economic Journal 108, November 1998, 1686-1706.

Marsh, Ian, and Ceire O'Rourke, title, Presented at the Equity and Currency Microstructure Conference, Oslo, September 2005.

McCallum, Bennett T. "A Reconsideration of the Uncovered Interest Parity Relationship." Journal of Monetary Economics 33, 1994, 105-132.

Meese, Richard A. and Rogoff, Kenneth. "Empriical Exchange Rate Models of the Seventies: Do they fit out of sample?" Journal of International Economics 14, February 1983, 3-24.

Milgrom, Paul, and Nancy Stokey, “Information, Trade, and Common Knowledge," Journal of Economic Theory 26, 1982, 17-27.

Moore, Michael and Roche, Maurice. "Less of a Puzzle: A New Look at the Forward Forex Market." Journal of International Economics 58, 2002, pp, 387-411.

Morris, Stephen, "Trade with Heterogeneous Prior Beliefs and Asymmetric Information," Econometrica 62, 1994, 1327-1347.

Mundell, Robert. "Capital Mobility and Stabilization Policy Under Fixed and Flexible Exchange Rates." Canadian Journal of Economics and Political Science 29, 1963, 475-85.

Murphy, K. and R. Topel "Estimation and Inference in Two Step Econometric Models." Journal of Business and Economic Statistics, 3, 1985, 370-379.

Missa, Michael. The Exchange Rate, the Balance of Payments and Monetary and Fiscal Policy Under a Regime of Controlled Floating." Scandianvian Journal of Economics 2, 1976: 229-248.

Muth, John F. "Optimal Properties of Exponentially Weighted Forecasts." Journal of the American Statistical Association 55, June 1960, 315-335.

Obstfeld, Maurice, and Rogoff, Kenneth. Exchange Rate Dynamics Redux. Journal of Political Economy 3, 1995, 624-660.

Obstfeld, Maurice, and Rogoff, Kenneth. "Risk and Exchange Rates." NBER Working Paper 6694, August 1998.

Obstfeld, Maurice, and Rogoff, Kenneth. Foundations of International Macroeconomics (M.I.T. Press, Cambridge: 2003).

Onur, Esen, "A Dynamic Model of the Foreign Exchange Market," Mimeo, University of California Davis, 2008.

Osler, Carol L. "Exchange Rate Dynamics and Speculators' Horizons." Journal of International Money and Finance 14, 1995, 695-719.

, "Short-term Speculators and the Puzzling Behavior of Exchange Rates." Journal of International Economics 45, 1998, 37-57.

, "Currency Orders and Exchange Rate Dynamics: An Explanation for the Predictive Success of Technical Analysis.” Journal of Finance 58, 2003, 1791-1819.

"Stop-Loss Orders and Price Cascades in Currency Markets," Journal of International Money and Finance 24, 2005, 219-241.'

"Macro Lessons from Microstructure," International Journal of Finance and Economics, 2006. 
"Foreign Exchange Microstructure: A Survey of the Empirical Literature,"

Forthcoming, Encyclopedia of Complexity and System Science (Springer: 2008).

Osler, Carol L., Alexander Mende, and Lukas Menkhoff, "Price Discovery in Currency Markets," Typescript 2008.

Pasquariello, Paolo, and Clara Vega, "Informed and Strategic Order Flow in the Bond Markets," Working Paper (October 2005).

Popper, K., 1959. The Logic of Scientific Discovery (Routledge, United Kingdom).

Rogoff, Kenneth S. “The Purchasing Power Parity Puzzle.” Journal of Economic Literature 34, 1996, 647-668.

Sarno, Lucio, and Mark P. Taylor, "Forward Bias and Non-Linearities (?)," Warwick University Working paper, 2004.

Shleifer, Andrei. “Do Demand Curves Slope Down?” The Journal of Finance 41, 1986, 579-90.

Wooldridge, Jeffrey M. "On the application of robust, regression- based diagnostics to models of conditional means and conditional variances," Journal of Econometrics, 47(1), 1991, 5-46.

Yates, J. Frank, Judgment and Decision Making. Prentice Hall (Englewood Cliffs New Jersey: 1988). 


\section{Figure 1: Take-Profit Orders Create a Currency Demand Curve}

The figure plots open the cumulative value of all dollar-yen take-profit orders at Royal Bank of Scotland on January 26, 2000, at 20:53 GMT. The horizontal axis plots the exchange rate, with the contemporaneous market midrate, $¥ 105.77 / \$$, shown by the vertical line. The vertical axis represents the cumulative dollar value of orders, measured in millions.

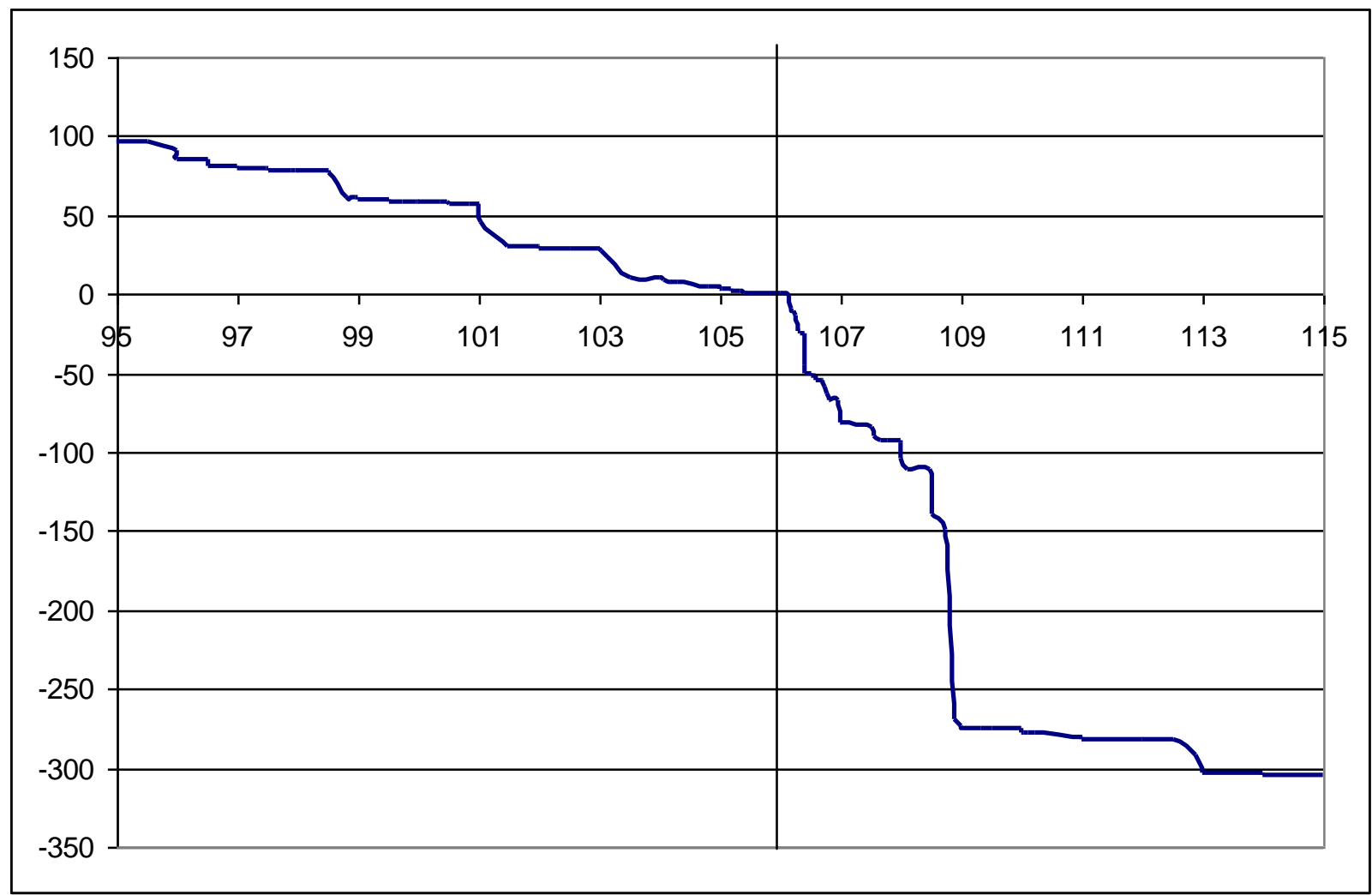




\section{Figure 2: Welfare and Speculative Activity}

The figure shows how unconditional expected welfare $E\{W\}$, is related to aggregate speculative activity, as measured by $\lambda$. ( $E\{W\}$ has been multiplied by 100 for convenience.) Equilibrium combinations of $E\{W\}$ and $\lambda$ are plotted for the following parameter values: $S D(\varepsilon)=6.0 ; S D(\eta)=0.4$; $\rho=0.85 ; \theta=5$. These parameters are consistent with the calibrated model simulated in Section IV.

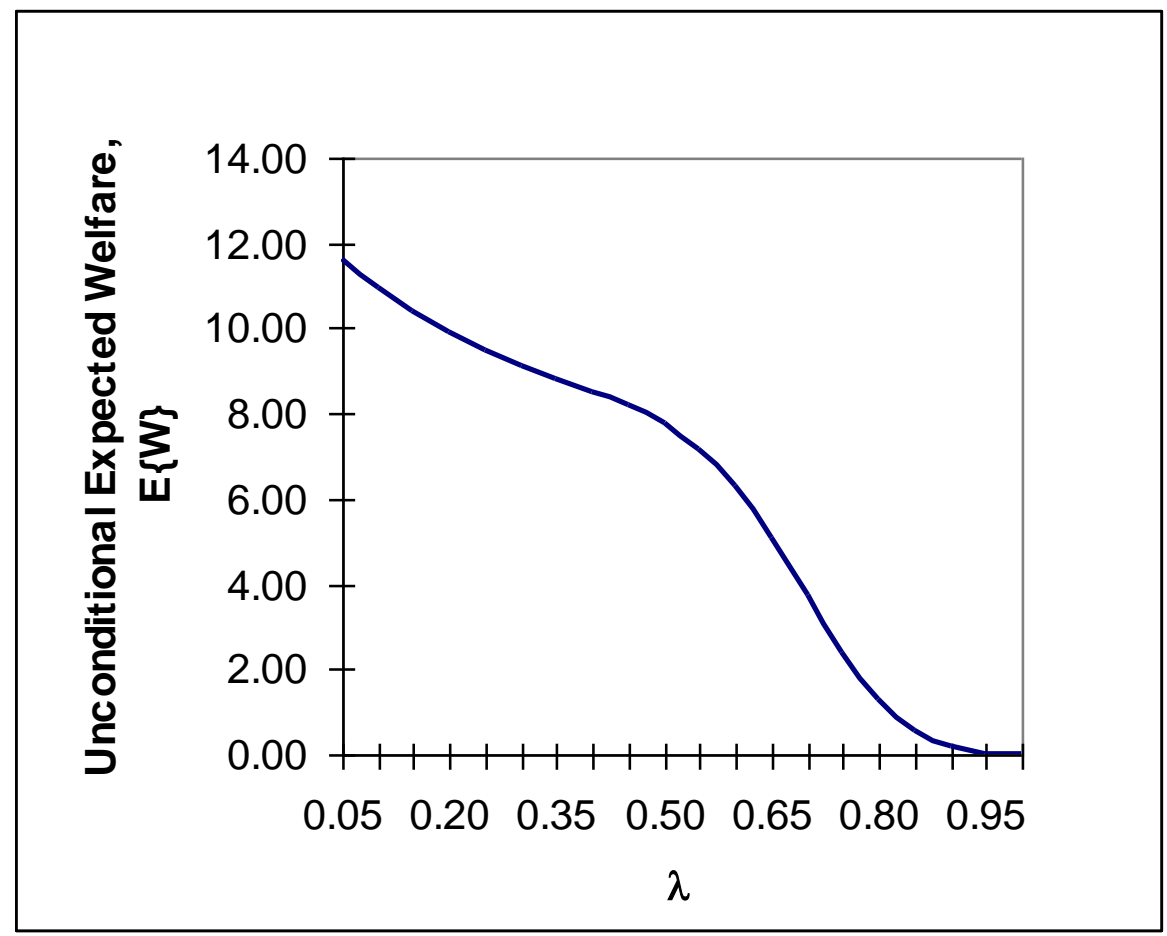




\section{Figure 3: Welfare and the Number of Speculators}

The figure shows the equilibrium number of speculators, $N$, for various values of welfare in alternative speculative activities, $W^{*}$. ( $W^{*}$, has been multiplied by 100 for convenience.) As welfare in other markets increases, currency speculators choose to leave the market. The underlying parameters for this simulation are those of Figure 2: $S D(\varepsilon)=6.0 ; S D(\eta)=0.4 ; \rho=0.85 ; \theta=5$.

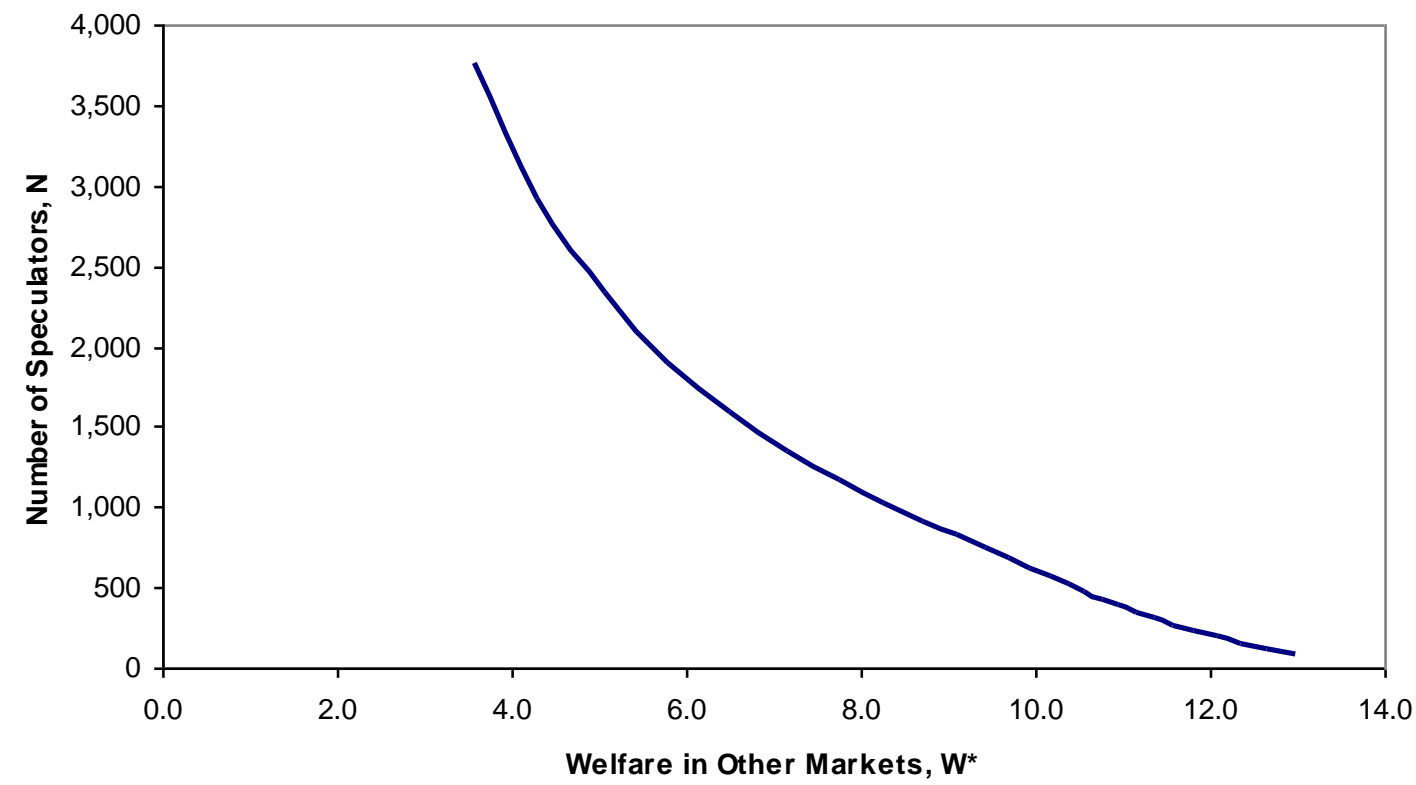




\section{Table 1: The Model and the Macro Anomalies}

The table shows properties of model equilibria under calibrated simulations. Base case parameters for both panels: $\sigma_{\varepsilon}=6.0 ; \sigma_{\eta}=0.342 ; \rho=0.89$. The model's final exogenous variable is $W^{*}$, welfare in alternative speculative markets. In the first panel we choose to vary $\lambda$, which is monotonically related to $W^{*}$, rather than vary $W^{*}$ itself. In the second panel we set $\lambda=0.9$ and vary $I / K$.

$\begin{array}{ccccccccc}\lambda & I / K & S D(\varepsilon) & \beta & S D(d) & S D(r p) & \begin{array}{c}\text { Corr } \\ \left(\Delta s_{t}, \Delta s_{t-1}\right)\end{array} & \begin{array}{c}\text { Corr } \\ \left(r p_{t}, r p_{t-1}\right)\end{array} & \begin{array}{c}\text { Corr } \\ \left(\Delta s_{t}, \mathrm{FX}_{t}\right)\end{array} \\ & & & & & & & & \\ 0.95 & 0 & 8.81 & 0.68 & 0.74 & 0.15 & -0.01 & 0.99 & -0.025 \\ 0.90 & 0 & 8.42 & 0.50 & 0.74 & 0.33 & -0.01 & 0.96 & -0.025 \\ 0.80 & 0 & 7.42 & 0.31 & 0.74 & 0.66 & -0.04 & 0.88 & -0.028 \\ 0.70 & 0 & 6.51 & 0.20 & 0.74 & 0.99 & -0.09 & 0.78 & -0.033 \\ & & & & & & & & \\ 0.90 & 0 & 8.42 & 0.50 & 0.74 & 0.33 & -0.01 & 0.96 & -0.025 \\ 0.90 & 5 & 7.84 & 0.27 & 0.74 & 0.22 & -0.02 & 0.93 & -0.027 \\ 0.90 & 10 & 6.93 & 0.05 & 0.74 & 0.16 & -0.03 & 0.90 & -0.018 \\ 0.90 & 15 & 5.54 & -0.17 & 0.74 & 0.21 & -0.04 & 0.96 & 0.011 \\ 0.90 & 20 & 3.00 & -0.40 & 0.74 & 0.32 & -0.05 & 0.99 & 0.010 \\ & & & & & & & & \\ 0.90 & 0 & 8.42 & 0.50 & 0.74 & 0.33 & -0.01 & 0.96 & -0.025 \\ 0.90 & 0 & 6.00 & 0.50 & 0.74 & 0.38 & -0.04 & 0.82 & -0.058 \\ 0.90 & 0 & 4.00 & 0.50 & 0.74 & 0.58 & -0.07 & 0.83 & -0.105 \\ 0.90 & 0 & 2.00 & 0.50 & 0.74 & 0.62 & -0.08 & 0.984 & -0.224\end{array}$




\section{Table 2: Econometric Estimates of the Standard Risk Premium Equation}

The table shows econometric estimates of the following equation:

$$
x r_{t+1}=\alpha+\psi d_{t}+\xi_{t+1}
$$

where $x r_{t+1}$ is the excess return to a currency, $d_{t}$ is the interest differential on three-month eurocurrency deposits relative to the U.S. (maturity-adjusted, continuous-time equivalents of quoted annual rates), and $\xi_{t+1}$ is a random disturbance. Quarterly data from April 1978 through April 2003.

\begin{tabular}{|c|c|c|c|}
\hline & Coefficient & $\begin{array}{c}\text { Newey- } \\
\text { West } \\
\text { Standard } \\
\text { Error }\end{array}$ & $\begin{array}{c}\text { Marginal } \\
\text { Significance }\end{array}$ \\
\hline \multicolumn{4}{|l|}{ DEM } \\
\hline$\psi$ & -1.625 & 0.669 & 0.017 \\
\hline Adjusted $R^{2}$ & \multicolumn{2}{|c|}{0.036} & \\
\hline Log-Likelihood & \multicolumn{2}{|c|}{1.435} & \\
\hline \multicolumn{4}{|l|}{ JPY } \\
\hline$\psi$ & -4.105 & 0.763 & 0.000 \\
\hline Adjusted $R^{2}$ & \multicolumn{2}{|c|}{0.143} & \\
\hline Log-Likelihood & \multicolumn{2}{|c|}{1.322} & \\
\hline \multicolumn{4}{|l|}{ CHF } \\
\hline$\psi$ & -2.109 & 0.596 & 0.001 \\
\hline Adjusted $R^{2}$ & \multicolumn{2}{|c|}{0.078} & \\
\hline Log-Likelihood & \multicolumn{2}{|c|}{1.366} & \\
\hline \multicolumn{4}{|l|}{ GBP } \\
\hline$\psi$ & -3.230 & 1.171 & 0.007 \\
\hline Adjusted $R^{2}$ & \multicolumn{2}{|c|}{0.125} & \\
\hline Log-Likelihood & \multicolumn{2}{|c|}{1.594} & \\
\hline \multicolumn{4}{|l|}{ CAD } \\
\hline$\psi$ & -1.961 & 0.490 & 0.000 \\
\hline Adjusted $R^{2}$ & \multicolumn{2}{|c|}{0.105} & \\
\hline Log-Likelihood & \multicolumn{2}{|c|}{2.407} & \\
\hline
\end{tabular}


Table 3: Econometric Estimates of the Model

Table shows econometric estimates associated with the empirical version of the following equation:

$$
x r_{t+1}=\alpha+\delta\left(E_{t+1} \bar{S}_{t+2}-E_{t} \bar{s}_{t+1}\right)+(1-\lambda)\left(E_{t} \bar{S}_{t+1}-s_{t}\right)+(\beta-1) d_{t}+v_{t+1}
$$

Interest differentials are for three-month eurocurrency deposits relative to the U.S. (maturity-adjusted, continuous-time equivalents of quoted annual rates). Quarterly data from April 1978 through April 2003 include three-month euro-market interest rates and producer prices, as well as exchange rates. Standard errors are in parenthesis. The symbols *,**, and *** indicate significance at the $10 \%, 5 \%$ and $1 \%$ respectively. The Likelihood Ratio test is based on the Log-Likelihood function values (at the estimated parameters) from the specifications in Table 2 and 3. The Hausman (1978) is a test for endogeneity while the AR and ARCH test, described in Wooldridge (1991), are for detecting dynamic misspecification in the conditional mean and variance respectively. Columns highlighted in bold represent the statistically most relevant results.

\begin{tabular}{|c|c|c|c|c|c|c|c|c|c|c|}
\hline \multirow[t]{2}{*}{ Coefficients/Tests } & \multicolumn{2}{|c|}{ United Kingdom } & \multicolumn{2}{|c|}{ Switzerland } & \multicolumn{2}{|c|}{ Germany } & \multicolumn{2}{|c|}{ Japan } & \multicolumn{2}{|c|}{ Canada } \\
\hline & QML & ML-2S & QML & ML-2S & QML & ML-2S & QML & ML-2S & QML & ML-2S \\
\hline \multirow[t]{2}{*}{$\alpha+(1-\lambda) * \mathrm{M}$} & $-0.111^{\star *}$ & $-0.041^{\star \star \star}$ & -0.032 & 0.011 & 0.079 & $0.166^{\star \star *}$ & $0.184^{\star *}$ & $0.209^{\star}$ & -0.035 & $0.107^{* * *}$ \\
\hline & $(0.047)$ & $(0.016)$ & $(0.085)$ & $(0.063)$ & $(0.084)$ & $(0.050)$ & $(0.086)$ & (0.119) & $(0.052)$ & $(0.030)$ \\
\hline \multirow[t]{2}{*}{$\delta$} & $3.147^{\star \star \star}$ & $1.136^{\star \star}$ & $1.984^{\star \star \star}$ & 1.813 & $2.417^{\star \star}$ & $2.337^{\star *}$ & $1.948^{*}$ & -1.633 & $0.810^{\star \star \star *}$ & -0.633 \\
\hline & $(0.750)$ & $(0.567)$ & $(0.501)$ & (1.701) & (0.939) & (1.176) & (1.117) & (1.915) & $(0.258)$ & $(0.643)$ \\
\hline \multirow[t]{2}{*}{$\lambda$} & $0.890^{* * *}$ & $0.968^{\star \star \star}$ & $0.904^{\star \star \star}$ & $0.925^{\star \star \star}$ & $0.894^{\star \star \star}$ & $0.904^{\star * *}$ & $0.947^{* * *}$ & $0.943^{\star \star *}$ & $0.878^{\star \star *}$ & $0.878^{* * *}$ \\
\hline & $(0.026)$ & $(0.044)$ & $(0.024)$ & $(0.043)$ & $(0.026)$ & $(0.033)$ & $(0.025)$ & $(0.026)$ & $(0.022)$ & (0.043) \\
\hline \multirow[t]{2}{*}{$\beta$} & $-2.016^{* \star \star}$ & $-1.674^{\star}$ & $-1.823^{\star \star *}$ & $-1.807^{*}$ & $-1.260^{\star *}$ & $-1.459^{*}$ & $-2.118^{\star * *}$ & $-3.749^{\star \star *}$ & $-1.196^{\star \star \star}$ & $-1.614^{* *}$ \\
\hline & $(0.475)$ & $(0.876)$ & $(0.422)$ & (1.097) & (0.541) & $(0.846)$ & $(0.538)$ & (1.015) & $(0.349)$ & $(0.763)$ \\
\hline$\sigma^{2} \times 10^{2}$ & 0.212 & 0.374 & 0.281 & 1.007 & 0.283 & 0.383 & 0.176 & 0.349 & 0.025 & 0.063 \\
\hline Log-Likelihood & 5.156 & 5.063 & 4.874 & 4.675 & 4.867 & 4.753 & 5.345 & 4.664 & 7.301 & 7.055 \\
\hline $\begin{array}{l}\text { Likelihood Ratio Test } \\
\text { p-value }\end{array}$ & $0.028^{* *}$ & $0.031^{\star *}$ & $0.030^{\star *}$ & $0.037^{* *}$ & $0.032^{\star *}$ & $0.036^{* *}$ & $0.018^{\star \star}$ & $0.035^{\star *}$ & $0.007^{\star \star \star}$ & $0.010^{* * *}$ \\
\hline Hausman Test & $0.004^{\star * *}$ & - & 0.970 & . & 0.845 & . & $0.007^{* \star *}$ & . & 0.823 & $\cdot$ \\
\hline Robust Test: AR[1:4] & 0.964 & 0.388 & 0.886 & 0.320 & 0.987 & 0.068 & 0.961 & 0.618 & 0.970 & 0.494 \\
\hline LM Test: AR[1:4] & 0.172 & 0.158 & 0.111 & 0.177 & 0.415 & $0.041^{* *}$ & 0.232 & 0.483 & 0.468 & 0.360 \\
\hline Ljung-Box: AR[1:10] & 0.404 & 0.454 & 0.251 & 0.325 & 0.402 & 0.166 & 0.975 & 0.999 & 0.874 & 0.858 \\
\hline Robust Test: ARCH[1:4] & 0.656 & 0.746 & 0.677 & 0.876 & 0.408 & 0.680 & 0.620 & 0.614 & 0.103 & 0.650 \\
\hline LM Test: ARCH[1:4] & 0.173 & $0.035^{* *}$ & 0.098 & 0.257 & $0.011^{\star *}$ & 0.157 & $0.098^{*}$ & 0.257 & $0.048^{\star *}$ & 0.255 \\
\hline Ljung-Box: ARCH[1:10] & 0.976 & 0.317 & 0.599 & 0.543 & 0.063 & 0.516 & 0.862 & 0.895 & 0.129 & 0.997 \\
\hline
\end{tabular}




\section{Appendix A: Solution Details}

Our model implies the following difference equation:

(A.1) $\quad \mathrm{E}_{\mathrm{t}} \mathrm{s}_{\mathrm{t}+1}-(1+\mathrm{K} / \mathrm{Q}) \mathrm{s}_{\mathrm{t}}-\mathrm{E}_{\mathrm{t}-1} \mathrm{~s}_{\mathrm{t}}+\mathrm{s}_{\mathrm{t}-1}=-\mathrm{X}_{\mathrm{t}}$

with $X_{t}=\left[C_{t}-Q\left(d_{t}-d_{t-1}\right)\right] / Q$ and $Q \equiv N q$.

To find the solution, first take expectations of (A.1) as of time $t-1$, and denote by $F$ the forward operator which increases the date on $\mathrm{s}$ but not the date on the expectations operator $\mathrm{E}$ and by $\mathrm{L}=\mathrm{F}^{-1}$ the lag operator that decreases the date on $\mathrm{s}$ but does not change the date of the expectations operator. Then collect terms:

By factorization:

$$
\left[\mathrm{F}^{2}-(2+\mathrm{K} / \mathrm{Q}) \mathrm{F}+1\right] \mathrm{LE}_{\mathrm{t}-1} \mathrm{~s}_{\mathrm{t}}=-\mathrm{E}_{\mathrm{t}-1} \mathrm{X}_{\mathrm{t}}
$$

(A.2) $\quad(\mathrm{F}-\lambda)\left(\mathrm{F}-\frac{1}{\lambda}\right) \mathrm{LE}_{\mathrm{t}-1} \mathrm{~S}_{\mathrm{t}}=-\mathrm{E}_{\mathrm{t}-1} \mathrm{X}_{\mathrm{t}}$

where $\lambda$ is the smaller root of the characteristic equation: $\lambda^{2}-(2+K / Q) \lambda+1=0$.

Multiply (A.2) through by $-\lambda /(1-\lambda \mathrm{F})$ and expand to get:

$$
E_{t-1} s_{t}=\lambda s_{t-1}+\lambda \sum_{j=0}^{\infty} \lambda^{j} E_{t-1} X_{t+j}+J \lambda^{-t}
$$

where $\mathrm{J}$ is an arbitrary constant. With the assumption of no explosive bubbles, $\mathrm{J}=0$. When (A.3), with $\mathrm{J}=0$, is used to substitute in (A.1) for $\mathrm{E}_{\mathrm{t}-1} \mathrm{~s}_{\mathrm{t}}$ and, with a suitable change in the time index, for $\mathrm{E}_{\mathrm{t}} \mathrm{S}_{\mathrm{t}+1}$, the resulting expression after collecting terms is:

$$
\left(1-\lambda+\frac{K}{Q}\right) s_{t}=(1-\lambda) s_{t-1}+X_{t}+\sum_{j=0}^{\infty} \lambda^{j+1} E_{t} X_{t+1+j}-\lambda \sum_{j=0}^{\infty} \lambda^{j} E_{t-1} X_{t+j}
$$

From the factorization, the sum of the roots can be written $\lambda+\frac{1}{\lambda}=2+\frac{K}{Q}$ and so:

$$
1-\lambda+\frac{K}{Q}=\frac{(1-\lambda)}{\lambda}
$$

and

$$
\frac{\lambda}{(1-\lambda)}=(1-\lambda) \frac{Q}{K}
$$

From (A.5) and (A.6)

$$
\frac{1}{\left(1-\lambda+\frac{K}{Q}\right)}=(1-\lambda) \frac{Q}{K}
$$

Multiply both sides of (A.4) by (A.7), and note that $(1-\lambda)^{2} \mathrm{Q} / \mathrm{K}=\lambda$, to get

$$
s_{t}=\lambda s_{t-1}+(1-\lambda) \frac{Q}{K} \sum_{j=0}^{\infty} \lambda^{j}\left[E_{t} X_{t+j}-\lambda E_{t-1} X_{t+j}\right]
$$

or substituting for $\mathrm{X}_{\mathrm{t}}=\left[\mathrm{C}_{\mathrm{t}}-\mathrm{Q} \Delta \mathrm{d}_{\mathrm{t}}\right] / \mathrm{Q}$, and noting again that $\mathrm{Q} / \mathrm{K}=\lambda /(1-\lambda)^{2}$,

$$
\begin{array}{r}
\mathrm{s}_{\mathrm{t}}=\lambda \mathrm{s}_{\mathrm{t}-1}+(1-\lambda) \sum_{j=0}^{\infty} \lambda^{j}\left(E_{t} C_{t+j}-\lambda E_{t-1} C_{t+j}\right) / K \\
-\frac{\lambda}{1-\lambda} \sum_{j=0}^{\infty} \lambda^{j}\left(E_{t} \Delta d_{t+j}-\lambda E_{t-1} \Delta d_{t+j}\right)
\end{array}
$$

Assume that $C_{t}$ is subject to both permanent and transitory shocks, as postulated by Muth (1960). His model can be written:

$$
\begin{aligned}
& C_{t}=A_{t}+u_{t} \\
& A_{t}=A_{t-1}+v_{t} .
\end{aligned}
$$


$\mathrm{C}_{\mathrm{t}}$ is observed but not $\mathrm{u}_{\mathrm{t}}$ and $\mathrm{v}_{\mathrm{t}}$ separately. Assume initially that $\mathrm{u}$ and $\mathrm{v}$ are i.i.d. random variables with zero means and variances $\sigma_{\mathrm{u}}{ }^{2}$ and $\sigma_{\mathrm{v}}{ }^{2}$, respectively. ${ }^{21}$ In that case, Muth proved that the optimal forecast of $\mathrm{C}$ is adjusted adaptively:

$$
\mathrm{E}_{\mathrm{t}} \mathrm{C}_{\mathrm{t}+1}=\gamma \mathrm{C}_{\mathrm{t}}+(1-\gamma) \mathrm{E}_{\mathrm{t}-1} \mathrm{C}_{\mathrm{t}}
$$

where $\mathrm{E}_{\mathrm{t}}$ denotes an expected value at time $\mathrm{t}$ and $\gamma(0<\gamma<1)$ is an increasing function of and $\sigma_{\mathrm{v}}{ }^{2} / \sigma_{\mathrm{u}}{ }^{2}$. If most of the variability is transitory, then $\gamma$ is close to 0 ; if most of the variability is permanent, then $\gamma$ is close to 1 . It is also the case with the zero means of $u$ and $v$ that $E_{t} C_{t+j}=E_{t} C_{t+1}$ for $j=2,3, \ldots$ The summation involving $\mathrm{C}$ terms can then be written

$$
\begin{aligned}
(1-\lambda) \sum_{j=0}^{\infty} & \lambda^{j}\left(E_{t} C_{t+j}-\lambda E_{t-1} C_{t+j}\right) / K=\left[(1-\lambda) \mathrm{C}_{\mathrm{t}}+\lambda \mathrm{E}_{\mathrm{t}} \mathrm{C}_{\mathrm{t}+1}-\lambda \mathrm{E}_{\mathrm{t}-1} \mathrm{C}_{\mathrm{t}}\right] / \mathrm{K} \\
= & {\left[(1-\lambda)\left(\mathrm{C}_{\mathrm{t}}-\mathrm{E}_{\mathrm{t}} \mathrm{C}_{\mathrm{t}+1}\right)+\mathrm{E}_{\mathrm{t}} \mathrm{C}_{\mathrm{t}+1}-\lambda \mathrm{E}_{\mathrm{t}-1} \mathrm{C}_{\mathrm{t}}\right] / \mathrm{K} } \\
= & \mathrm{E}_{\mathrm{t}} \bar{S}_{\mathrm{t}+1}-\lambda \mathrm{E}_{\mathrm{t}-1} \bar{S}_{\mathrm{t}}+(1-\lambda) \varepsilon_{\mathrm{t}}
\end{aligned}
$$

The last line in (A.9) is obtained from the following definitions. Define $\mathrm{E}_{\mathrm{t}} \mathrm{C}_{\mathrm{t}+1} / \mathrm{K}_{\text {b }} \mathrm{E}_{\mathrm{t}} \bar{s}_{\mathrm{t}+1}$ and $\mathrm{E}_{\mathrm{t}-}$

${ }_{1} \mathrm{C}_{\mathrm{t}} / \mathrm{K}$ by $\mathrm{E}_{\mathrm{t}-1} \bar{S}_{\mathrm{t}}$. Also let $\varepsilon_{\mathrm{t}}=\left[\mathrm{C}_{\mathrm{t}}-\mathrm{E}_{\mathrm{t}} \mathrm{C}_{\mathrm{t}+1}\right] / \mathrm{K}$ denote the perceived transitory shock.

For the interest differential, we assume that $d_{t}=\rho d_{t-1}+\eta_{t}$. In that case

$$
\begin{aligned}
& d_{t}-d_{t-1}=(\rho-1) d_{t-1}+\eta_{t}, \\
& E_{t-1}\left(d_{t}-d_{t-1}\right)=(\rho-1) d_{t-1}, \\
& E_{t}\left(d_{t+j}-d_{t-1+j}\right)=(\rho-1) \rho^{j-1} d_{t}=(\rho-1)\left(\rho^{j} d_{t-1}+\rho^{j-1} \eta_{t}\right) \\
& E_{t-1}\left(d_{t+j}-d_{t-1+j}\right)=(\rho-1) \rho^{j} d_{t-1}
\end{aligned}
$$

With these substitutions and using (A9) in (A.8), the solution can be written:

$$
\mathrm{s}_{\mathrm{t}}-\mathrm{E}_{\mathrm{t}} \bar{s}_{\mathrm{t}+1}=\lambda\left(\mathrm{s}_{\mathrm{t}-1}-\mathrm{E}_{\mathrm{t}-1} \bar{S}_{\mathrm{t}}\right)+(1-\lambda) \varepsilon_{\mathrm{t}}-\frac{\lambda}{1-\rho \lambda} \eta_{\mathrm{t}}+\frac{\lambda(1-\rho)}{1-\rho \lambda} \mathrm{d}_{\mathrm{t}-1} .
$$

(A.10) can also be written alternatively as:

$$
\mathrm{s}_{\mathrm{t}}-\mathrm{s}_{\mathrm{t}-1}=\left(\mathrm{E}_{\mathrm{t}} \bar{S}_{\mathrm{t}+1}-\mathrm{E}_{\mathrm{t}-1} \bar{S}_{\mathrm{t}}\right)+(1-\lambda)\left(\mathrm{E}_{\mathrm{t}-1} \bar{S}_{\mathrm{t}}-\mathrm{s}_{\mathrm{t}-1}\right)+(1-\lambda) \varepsilon_{\mathrm{t}}-\frac{\lambda}{1-\rho \lambda} \eta_{\mathrm{t}}+\frac{\lambda(1-\rho)}{1-\rho \lambda} \mathrm{d}_{\mathrm{t}-1} .
$$

Expected Welfare

Conditional expected welfare is given as:

(A.11) $\quad \mathrm{W}_{\mathrm{t}}=\mathrm{E}_{\mathrm{t}}\left(\pi_{\mathrm{t}+1}\right)-(\theta / 2) \operatorname{Var}_{\mathrm{t}}\left(\pi_{\mathrm{t}+1}\right)$

The profitability of position $b_{t}$ is:

(A.12) $\quad \pi_{t+1}=b_{t}\left[s_{t+1}-s_{t}-d_{t}\right]$.

The position itself is given by

$$
\mathrm{b}_{\mathrm{t}}=\mathrm{qrp_{ \textrm {t } }} \quad \text { where } \mathrm{q}=\frac{1}{\theta \operatorname{Var}(\mathrm{s})}
$$

The risk premium $\mathrm{rp}_{\mathrm{t}}$ is defined by
(A.14)
$\mathrm{rp}_{\mathrm{t}}=\mathrm{E}_{\mathrm{t}} \mathrm{s}_{\mathrm{t}+1}-\mathrm{s}_{\mathrm{t}}-\mathrm{d}_{\mathrm{t}}$
with $d_{t}=r_{t}-r^{*}$.

The unanticipated change in the exchange rate takes the form:

$$
v_{t+1}=(1-\lambda) \varepsilon_{t+1}-\frac{\lambda}{1-\rho \lambda} \eta_{t+1}
$$

Therefore

$$
\mathrm{s}_{\mathrm{t}+1}=\mathrm{E}_{\mathrm{t}} \mathrm{s}_{\mathrm{t}+1}+v_{\mathrm{t}+1}
$$

and

$$
\operatorname{Var}(\mathrm{s})=(1-\lambda)^{2} \operatorname{var}(\varepsilon)+\frac{\lambda^{2}}{(1-\rho \lambda)^{2}} \operatorname{var}(\eta)=\operatorname{var}(v)
$$

\footnotetext{
${ }^{21}$ An alternative formulation with fully anticipated changes in $\mathrm{C}$ occurs when $\mathrm{u}=0$ and $\mathrm{v}$ equals a known value. An intermediate case arises when $\mathrm{v}$ has a non-zero expected value but there are also stochastic unanticipated changes in $\mathrm{C}$.
} 
The payoff to a rational speculative position, after substituting (A.13), (A.14) and (A.16) into (A.12) is:

(A.18) $\quad \pi_{\mathrm{t}+1}=\mathrm{qrp} \mathrm{rp}_{\mathrm{t}}\left[\mathrm{rp}_{\mathrm{t}}+\mathrm{v}_{\mathrm{t}+1}\right]$

From (A.18), we have
(A.19)
$\mathrm{E}_{\mathrm{t}}\left(\pi_{\mathrm{t}+1}\right)=\mathrm{q}\left(\mathrm{rp}_{\mathrm{t}}\right)^{2}$
(A.20)
$\operatorname{Var}_{\mathrm{t}}\left(\pi_{\mathrm{t}+1}\right)=\mathrm{q}^{2}\left(\mathrm{rp}_{\mathrm{t}}\right)^{2} \operatorname{Var}(\mathrm{s})$

Substituting these into (A.11) and simplifying yields

$$
\mathrm{W}_{\mathrm{t}}=\frac{\left(r p_{t}\right)^{2}}{2 \theta \operatorname{Var}(s)}
$$

In the model, since $\mathrm{E}_{\mathrm{t}} \bar{S}_{\mathrm{t}+1}=\bar{S}_{\mathrm{t}}$, the risk premium is given by:

$$
\mathrm{rp}_{\mathrm{t}}=(1-\lambda)\left(\bar{s}_{\mathrm{t}}-\mathrm{s}_{\mathrm{t}}\right)+(\beta-1) \mathrm{d}_{\mathrm{t}} \quad \text { where } \beta=\frac{\lambda(1-\rho)}{1-\rho \lambda}
$$

Substitute this into (A.21) and take the unconditional expected value:

$$
\mathrm{E}\left(\mathrm{W}_{\mathrm{t}}\right)=\frac{(1-\lambda)^{2} E\left\{\left(\overline{s_{t}}-s_{t}\right)-[1 /(1-\lambda \rho)] d_{t}\right\}^{2}}{2 \theta \operatorname{Var}(s)}
$$

The numerator in (A.23) can be written

$$
(1-\lambda)^{2}\left\{\mathrm{E}\left(\mathrm{s}_{\mathrm{t}}-\bar{S}_{\mathrm{t}}\right)^{2}+\frac{2}{(1-\rho \lambda)} \mathrm{Ed}_{\mathrm{t}}\left(\mathrm{s}_{\mathrm{t}}-\bar{S}_{\mathrm{t}}\right)+\frac{1}{(1-\rho \lambda)^{2}} \mathrm{Ed}_{\mathrm{t}}^{2}\right\}
$$

with
(A.25)
$d_{t}=\rho d_{t-1}+\eta_{t}$
$0<\rho<1$.
(A.26)

$$
\mathrm{s}_{\mathrm{t}}-\bar{s}_{\mathrm{t}}=\lambda\left(\mathrm{s}_{\mathrm{t}-1}-\bar{S}_{\mathrm{t}-1}\right)+v_{\mathrm{t}}+\frac{\lambda(1-\rho)}{1-\rho \lambda} \mathrm{d}_{\mathrm{t}-1}
$$

To evaluate $E \mathrm{~d}_{\mathrm{t}}^{2}$, note from (A.25) that $\mathrm{d}_{\mathrm{t}}$ can be written in moving average form:

$$
d_{t}=\eta_{t}+\rho \eta_{t-1}+\rho^{2} \eta_{t-2}+\ldots
$$

Therefore, assuming independent, mean-zero $\eta$ 's:

$$
\mathrm{Ed}_{\mathrm{t}}^{2}=\operatorname{var}(\mathrm{d})=\frac{1}{1-\rho^{2}} \operatorname{var}(\eta)
$$

For the first term in (A.24), the moving average representation for $\left(\mathrm{s}_{\mathrm{t}}-\bar{S}_{\mathrm{t}}\right)$ can be written (with $\mathrm{b}=$

$$
\begin{aligned}
& \left.\frac{\lambda(1-\rho)}{1-\rho \lambda}\right): \\
& \quad \mathrm{s}_{\mathrm{t}}-\bar{s}_{\mathrm{t}}=v_{\mathrm{t}}+\lambda v_{\mathrm{t}-1}+\lambda^{2} v_{\mathrm{t}-2}+\ldots+\mathrm{bd}_{\mathrm{t}-1}+\lambda \mathrm{bd}_{\mathrm{t}-2}+\lambda^{2} \mathrm{bd}_{\mathrm{t}-3}+\lambda^{3} \mathrm{bd}_{\mathrm{t}-4} \quad \ldots
\end{aligned}
$$

Therefore:

$$
\begin{gathered}
\mathrm{E}\left(\mathrm{s}_{\mathrm{t}}-\bar{s}_{\mathrm{t}}\right)^{2}=\left(1+\lambda^{2}+\lambda^{4} \ldots\right) \operatorname{var}(v) \\
+\mathrm{b}^{2} \mathrm{E}\left[\mathrm{d}_{\mathrm{t}-1}{ }^{2}+\lambda^{2} \mathrm{~d}_{\mathrm{t}-2}{ }^{3}+\lambda^{4} \mathrm{~d}_{\mathrm{t}-3}{ }^{2} \ldots\right. \\
\quad+2 \lambda \mathrm{d}_{\mathrm{t}-1} \mathrm{~d}_{\mathrm{t}-2}+2 \lambda^{2} \mathrm{~d}_{\mathrm{t}-2} \mathrm{~d}_{\mathrm{t}-3}+2 \lambda^{5} \mathrm{~d}_{\mathrm{t}-3} \mathrm{~d}_{\mathrm{t}-4}+\ldots \\
\left.\quad+2 \lambda^{2} \mathrm{~d}_{\mathrm{t}-1} \mathrm{~d}_{\mathrm{t}-3}+2 \lambda^{4} \mathrm{~d}_{\mathrm{t}-2} \mathrm{~d}_{\mathrm{t}-4}+\ldots\right] \\
\quad+2 \mathrm{bE}\left[\lambda v_{\mathrm{t}-1 \mathrm{~d}_{\mathrm{t}-1}+\lambda^{2} v_{\mathrm{t}-2} \mathrm{~d}_{\mathrm{t}-1}+\lambda^{3} v_{\mathrm{t}-3} \mathrm{~d}_{\mathrm{t}-1}+\ldots}+\ldots\right. \\
\left.\quad+\lambda^{3} v_{\mathrm{t}-2} \mathrm{~d}_{\mathrm{t}-2}+\lambda^{4} v_{\mathrm{t}-3} \mathrm{~d}_{\mathrm{t}-2}+\ldots\right] \\
=\frac{1}{1-\lambda^{2}}\left\{\operatorname{var}(v)+\mathrm{b}^{2}\left[1+\frac{2 \rho \lambda}{1-\rho \lambda}\right] \operatorname{var}(\mathrm{d})-2 \mathrm{~b} \frac{\lambda}{1-\rho \lambda} \frac{\lambda}{1-\rho \lambda} \operatorname{var}(\eta)\right\} \\
=\frac{1}{1-\lambda^{2}}\left\{(1-\lambda)^{2} \operatorname{var}(\varepsilon)+\frac{\lambda^{2}}{(1-\rho \lambda)^{2}} \operatorname{var}(\eta)\right.
\end{gathered}
$$




$$
\begin{aligned}
& \left.+\left[\frac{\lambda^{2}(1-\rho)^{2}}{(1-\rho \lambda)^{3}} \frac{1+\rho \lambda}{1-\rho^{2}}-\frac{2 \lambda^{3}(1-\rho)}{(1-\rho \lambda)^{3}}\right] \operatorname{var}(\eta)\right\} \\
= & \frac{1-\lambda}{1+\lambda} \operatorname{var}(\varepsilon)+ \\
& \frac{\lambda^{2}\left[(1-\rho \lambda)\left(1-\rho^{2}\right)+(1-\rho)^{2}(1+\rho \lambda)-2 \lambda(1-\rho)\left(1-\rho^{2}\right)\right]}{\left(1-\lambda^{2}\right)(1-\rho \lambda)^{3}\left(1-\rho^{2}\right)} \operatorname{var}(\eta) \\
= & \frac{1-\lambda}{1+\lambda} \operatorname{var}(\varepsilon)+ \\
& \frac{\lambda^{2}(1-\rho)\left[(1-\rho \lambda)(1+\rho)+(1-\rho)(1+\rho \lambda)-2 \lambda\left(1-\rho^{2}\right)\right]}{\left(1-\lambda^{2}\right)(1-\rho \lambda)^{3}\left(1-\rho^{2}\right)} \operatorname{var}(\eta) \\
= & \frac{1-\lambda}{1+\lambda} \operatorname{var}(\varepsilon)+\frac{\lambda^{2}(1-\rho) 2(1-\lambda)}{\left(1-\lambda^{2}\right)(1-\rho \lambda)^{3}\left(1-\rho^{2}\right)} \operatorname{var}(\eta)
\end{aligned}
$$

$$
\mathrm{E}\left(\mathrm{s}_{\mathrm{t}}-\bar{s}_{\mathrm{t}}\right)^{2}=\frac{1-\lambda}{1+\lambda} \operatorname{var}(\varepsilon)+\frac{2 \lambda^{2}}{(1+\lambda)(1-\rho \lambda)^{3}(1+\rho)} \operatorname{var}(\eta)
$$

The foregoing used $E d_{t} d_{t-j}=\rho^{j} \operatorname{var}(d)$ and $E v_{t-j} d_{t}=-\frac{\lambda}{1-\rho \lambda} \rho^{j} \operatorname{var}(\eta)$.

For the middle term in (A.24)

$$
\begin{gathered}
\mathrm{E}\left(\mathrm{s}_{\mathrm{t}}-\bar{s}_{\mathrm{t}}\right) \mathrm{d}_{\mathrm{t}}=\mathrm{E}\left(v_{\mathrm{t}}+\lambda v_{\mathrm{t}-1}+\lambda^{2} v_{\mathrm{t}-2} \ldots \mathrm{bd}_{\mathrm{t}-1}+\lambda \mathrm{bd}_{\mathrm{t}-2}+\lambda^{2} \mathrm{bd}_{\mathrm{t}-3} \ldots\right) \mathrm{d}_{\mathrm{t}} \\
=-\frac{\lambda}{1-\rho \lambda}\left(1+\rho \lambda+(\rho \lambda)^{2}+\ldots\right) \operatorname{var}(\eta)+\mathrm{b} \rho\left(1+\rho \lambda+(\rho \lambda)^{2}+\ldots\right) \operatorname{var}(\mathrm{d}) \\
=\frac{-\lambda\left(1-\rho^{2}\right)+\rho \lambda(1-\rho)}{(1-\rho \lambda)^{2}} \operatorname{var}(\mathrm{d})=\frac{-\lambda(1-\rho)}{(1-\rho \lambda)^{2}} \operatorname{var}(\mathrm{d})
\end{gathered}
$$

$$
\mathrm{E}\left(\mathrm{s}_{\mathrm{t}}-\bar{s}_{\mathrm{t}}\right) \mathrm{d}_{\mathrm{t}}=\frac{-\lambda}{(1-\rho \lambda)^{2}(1+\rho)} \operatorname{var}(\eta)
$$

Note the negative unconditional covariance between the interest rate differential and deviations in the exchange rate from its long-run level. Higher domestic interest rates tend to be associated with an appreciated currency.

Putting (A.27), (A.28) and (A.29) into (A.24) and the result into (A.23) yields:

$$
\begin{aligned}
& 2 \theta \mathrm{E}\left(\mathrm{W}_{\mathrm{t}}\right)=\frac{(1-\lambda)^{3}}{1+\lambda} \frac{\operatorname{var}(\varepsilon)}{\operatorname{var}(v)} \\
& +\frac{(1-\lambda)^{2}}{(1-\rho \lambda)^{2}}\left[\frac{2 \lambda^{2}}{(1+\lambda)(1-\rho \lambda)(1+\rho)}-\frac{2 \lambda}{(1-\rho \lambda)(1+\rho)}+\frac{1}{1-\rho^{2}}\right] \frac{\operatorname{var}(\eta)}{\operatorname{var}(v)} \\
& =\frac{(1-\lambda)^{3}}{1+\lambda} \frac{\operatorname{var}(\varepsilon)}{\operatorname{var}(v)} \\
& +(1-\lambda)^{2}\left[\frac{2 \lambda^{2}(1-\rho)-2 \lambda(1+\lambda)(1-\rho)+(1+\lambda)(1-\rho \lambda)}{(1+\lambda)(1-\rho \lambda)^{3}\left(1-\rho^{2}\right)}\right] \frac{\operatorname{var}(\eta)}{\operatorname{var}(v)}
\end{aligned}
$$

Therefore

(A.30)

$$
\mathrm{E}\left(\mathrm{W}_{\mathrm{t}}\right)=\frac{(1-\lambda)^{3}}{2 \theta(1+\lambda)}\left[\frac{\operatorname{var}(\varepsilon)}{\operatorname{var}(v)}+\frac{(1+\rho \lambda)}{(1-\rho \lambda)^{3}\left(1-\rho^{2}\right)} \frac{\operatorname{var}(\eta)}{\operatorname{var}(v)}\right]
$$


Mapping between $\lambda$ and $\mathrm{N}$.

We can manipulate the characteristic equation, $\lambda^{2}-(2+\mathrm{K} / \mathrm{Nq}) \lambda+1=0$, to obtain

(A.31) $\quad \mathrm{N}=\mathrm{K} \lambda /\left(\mathrm{q}(1-\lambda)^{2}\right)$.

We also know that $\mathrm{q}=1 / \theta \operatorname{var}(v)$

and that $\operatorname{var}(v)=(1-\lambda)^{2} \operatorname{var}(\varepsilon)+(\lambda /(1-\rho \lambda))^{2} \operatorname{var}(\eta)$

Therefore, by substitution for $\mathrm{q}$ and $\operatorname{var}(v)$ in $(\mathrm{A} .31)$ :

$$
\mathrm{N}=\mathrm{K} \lambda \theta\left(\operatorname{var}(\varepsilon)+(\lambda /((1-\lambda)(1-\rho \lambda)))^{2} \operatorname{var}(\eta)\right) \text {. }
$$

This monotonic relationship between $\mathrm{N}$ and $\lambda$ was used to construct Figure 3 from the data underlying Figure 2. 